\title{
Increased hippocampal excitability and impaired spatial memory function in mice lacking VGLUT2 selectively in neurons defined by tyrosine hydroxylase promoter activity
}

\author{
Karin Nordenankar $\cdot$ Casey J. A. Smith-Anttila $\cdot$ Nadine Schweizer • \\ Thomas Viereckel $\cdot$ Carolina Birgner $\cdot$ Jana Mejia-Toiber • \\ Marisela Morales • Richardson N. Leao • Åsa Wallén-Mackenzie
}

Received: 12 September 2013/Accepted: 11 April 2014/Published online: 7 May 2014

(C) The Author(s) 2014. This article is published with open access at Springerlink.com

\begin{abstract}
Three populations of neurons expressing the vesicular glutamate transporter 2 (Vglut2) were recently described in the A10 area of the mouse midbrain, of which two populations were shown to express the gene encoding, the rate-limiting enzyme for catecholamine synthesis, tyrosine hydroxylase (TH).One of these populations (" $\mathrm{TH}-$ Vglut2 Class1") also expressed the dopamine transporter (DAT) gene while one did not ("TH-Vglut2 Class2"), and the remaining population did not express $T H$ at all ("Vglut2-only"). $T H$ is known to be expressed by a promoter which shows two phases of activation, a transient one early during embryonal development, and a later one
\end{abstract}

K. Nordenankar and C. J. A. Smith-Anttila contributed equally.

Electronic supplementary material The online version of this article (doi:10.1007/s00429-014-0778-9) contains supplementary material, which is available to authorized users.

K. Nordenankar · C. J. A. Smith-Anttila · N. Schweizer .

T. Viereckel · C. Birgner · A. Wallén-Mackenzie $(\bowtie)$

Unit of Functional Neurobiology and Unit of Developmental

Genetics, Biomedical Center, Department of Neuroscience,

Uppsala University, Box 593, S-751 24 Uppsala, Sweden

e-mail: asa.mackenzie@neuro.uu.se

J. Mejia-Toiber · M. Morales

National Institute on Drug Abuse, Intramural Research Program,

Neuronal Networks Section, 251 Bayview Boulevard, Baltimore, MD 21224, USA

R. N. Leao

Brain Institute, Federal University of Rio Grande do Norte,

Natal/RN 2155 - 59056-450, Brazil

R. N. Leao

Unit of Developmental Genetics, Biomedical Center,

Department of Neuroscience, Uppsala University, Box 593,

S-751 24 Uppsala, Sweden which gives rise to stable endogenous expression of the $\mathrm{TH}$ gene. The transient phase is, however, not specific to catecholaminergic neurons, a feature taken to advantage here as it enabled Vglut2 gene targeting within all three A10 populations expressing this gene, thus creating a new conditional knockout. These knockout mice showed impairment in spatial memory function. Electrophysiological analyses revealed a profound alteration of oscillatory activity in the CA3 region of the hippocampus. In addition to identifying a novel role for Vglut2 in hippocampus function, this study points to the need for improved genetic tools for targeting of the diversity of subpopulations of the A10 area.

Keywords Reward · Oscillations · Development · Midbrain · Mouse genetics

$\begin{array}{ll}\text { Abbreviations } \\ \beta-G a l & \beta \text {-Galactosidase } \\ \mathrm{CaPu} & \text { Caudate putamen } \\ \text { cKO } & \text { Conditional knockout } \\ \mathrm{CLi} & \text { Caudal linear nucleus } \\ \mathrm{Ctrl} & \text { Control } \\ \text { DA } & \text { Dopamine } \\ \text { DAB } & 3,3 \text {-Diaminobenzidine-4 } \\ \text { DAPI } & 4^{\prime}, 6^{\prime} \text {-Diamidino-2-phenylindole } \\ \text { DAT } & \text { Dopamine transporter } \\ \text { DOPAC } & 3,4-\text { Dihydroxyphenylacetic acid } \\ \text { DRG } & \text { Dorsal root ganglia } \\ \text { EPM } & \text { Elevated plus maze } \\ \text { FST } & \text { Forced swim test } \\ \text { GFP } & \text { Green fluorescent protein } \\ \text { HVA } & \text { Homovanillic acid } \\ \text { IF } & \text { Interfascicular nucleus } \\ \text { IHC } & \text { Immunohistochemistry }\end{array}$




$\begin{array}{ll}\text { IHC } & \text { Immunohistochemistry } \\ \text { KRB } & \text { Krebs-Ringer buffer } \\ \text { LFP } & \text { Local field potential } \\ \text { IVTA } & \text { Later ventral tegmental area } \\ \text { MFB } & \text { Medial forebrain bundle } \\ \text { NAcc } & \text { Nucleus accumbens } \\ \text { PB } & \text { Phosphate buffer } \\ \text { PFA } & \text { Paraformaldehyde } \\ \text { PFC } & \text { Prefrontal cortex } \\ \text { RLi } & \text { Rostral linear nucleus } \\ \text { RME } & \text { Reference memory error } \\ \text { SNc } & \text { Substantia nigra pars compacta } \\ \text { SSC } & \text { Saline-sodium citrate } \\ \text { TH } & \text { Tyrosine hydroxylase } \\ \text { TUJ1 } & \text { Beta-III-tubulin } \\ \text { Vglut2 } & \text { Vesicular glutamate transporter 2 } \\ \text { VIAAT } & \text { Vesicular inhibitory amino acid transporter } \\ \text { VTA } & \text { Ventral tegmental area } \\ \text { WME } & \text { Working memory error }\end{array}$

\section{Introduction}

The A10 area of the ventral midbrain is the home of the classical dopamine (DA) neurons that are important for motivation, reward, learning and memory via substantial projections into limbic and cognitive regions. A10 consists of the ventral tegmental area (VTA) and three midline nuclei, known as the interfascicular (IF), rostral linear (RLi) and caudal linear (CLi) nuclei, respectively (Fields et al. 2007; Ikemoto 2007). Recent studies have shown that the medial VTA together with IF and RLi, which collectively often are referred to simply as the VTA, are more heterogeneous in terms of cell populations than previously thought (Li et al. 2013). For example, three distinct neuronal populations expressing the vesicular glutamate transporter 2 (Vglut2, aka Slc17A6) gene, which confers a glutamatergic phenotype (Fremeau et al. 2004), have been identified within the VTA of the adult rat and mouse. Of these three VTA Vglut2-expressing (VTA-VGLUT2) populations, one appears to consist of purely glutamatergic neurons ("Glu-only" or "Vglut2-only") that show similar electrophysiological properties and projections as the neighbouring DA neurons (Hnasko et al. 2012; Kawano et al. 2006; Yamaguchi et al. 2007). The other two populations both express tyrosine hydroxylase $(\mathrm{TH})$, the ratelimiting enzyme in DA synthesis, along with Vglut2, but differ with regards to their expression of the dopamine transporter (DAT) (Li et al. 2013). Thus, the neurons in one VTA-VGLUT2 population coexpress $T H$ and DAT and have been named "TH-Vglut2 Class 1" neurons, while the other population contains neurons that do not express $D A T$ and are referred to as "TH-Vglut2 Class 2" neurons (Li et al. 2013). Both of these TH-Vglut2 populations presumably represent DA neurons that corelease glutamate [reviewed in (El Mestikawy et al. 2011; Hnasko and Edwards 2012)]. In addition to the unique property of expression in DA neurons, Vglut2 is distinct from its sister molecules Vglut1 and Vglut3 in that Vglut2 is the only isoform which can be broadly detected already at midgestation, including within the developing VTA (Birgner et al. 2010). The functional role of Vglut2 expression in DA neurons has been investigated by different laboratories using the Cre-LoxP-based conditional knockout technique (Wallén-Mackenzie et al. 2010) targeting DA neurons via DAT promoter-driven expression of Cre recombinase. Briefly summarized, these studies demonstrated that DATCre-mediated deletion of Vglut2 expression left motivation and memory parameters intact, while causing altered responses to sweet food and psychostimulants, thereby revealing a role for the glutamate-DA cophenotype in certain aspects of reward processing (Alsiö et al. 2011; Birgner et al. 2010; Fortin et al. 2012; Hnasko et al. 2010). Spatially, DAT-Cre is to date the most appropriate Credriver for targeting gene expression in DA neurons, but temporally, Vglut2 expression, detected in the VTA at embryonic day (E) 11, is more tuned with $T H$ expression (E11; Zetterström et al. (1997)) which precedes that of DAT (E14; Fauchey et al. (2000)) by several days. To explore the possibility of targeting Vglut2 in DA neurons already from midgestation, we therefore turned to a previously validated $\mathrm{TH}$-ires-Cre knock-in mouse (Lindeberg et al. 2004) known to recapitulate endogenous TH expression, and we could indeed verify this expected Cre activity. Somewhat surprisingly, ectopic Cre activity was also detected in the "Vglut2-only" neurons of the VTA. Thus, based on the promiscuity of the TH promoter, we hypothesized that we had a genetic tool at hand which we could use for targeting neurons within all three VTAVGLUT2 populations, i.e. "Vglut2-only", "TH-Vglut2 Class 1" and "TH-Vglut2 Class 2" neurons. Upon verification, we used behavioural, electrochemical and electrophysiological techniques to analyse this new conditional Vglut2 knockout mouse.

\section{Materials and methods}

Animal housing

All mice used in the study were housed in the animal facility at the BMC, Uppsala University, in accordance with the Swedish regulation guidelines (Animal Welfare Act SFS 1998:56) and European Union legislation (Convention ETS123 and Directive 2010/63/EU). Ethical 
approval was obtained from the Uppsala Animal Ethical Committee. The animals were housed by sex in standard Makrolon cages $(59 \times 38 \times 20 \mathrm{~cm})$ with aspen wood bedding (Scanbur AB Sollentuna, Sweden) and a wooden house. The temperature was kept at $21-22{ }^{\circ} \mathrm{C}$ with a humidity of $45-55 \%$. A $12 \mathrm{~h}$ light/12 h dark cycle was used, with lights on at $07.00 \mathrm{~h}$. The animals had ad libitum access to food (R36, Labfor, Lactamin, Vadstena, Sweden) and water.

\section{Generation of transgenic mice}

The Vglut $2^{f / f ; T H-C r e}$ mouse line was produced using the breeding procedure established for conditional knockout mice to ensure identical genetic background (Crusio 2004) by breeding the Th-IRES-Cre (here abbreviated as TH-Cre) knock-in mouse line (on a C57BL/6 J genetic background) (Lindeberg et al. 2004) to the Vglut $2^{f / f}$ mouse line (on a C57BL/6 J-SV129 genetic background) (Wallén-Mackenzie et al. 2009) thereby generating cKO (Vglut $2^{f / f ; T H-C r e+}$ ) and control ( Vglut $\left.2^{f / f ; T H-C r e-}\right)$ mice as littermates which allows for behavioural phenotyping and comparison between genotype groups (Wolfer et al. 2002). The generation of $V$ glut $2^{f / f ; T H-C r e}$ mouse line was described previously and it was demonstrated that a subset of $V g l u t 2^{f / f ; T H-}$ ${ }^{\mathrm{Cre}} \mathrm{cKO}$ mice have an itch phenotype at a late adult stage (Lagerstrom et al. 2010). None of the analyses in the current study included adult mice showing an itch phenotype. The Vglut $2^{f / f}$ mouse line was bred with the Tau ${ }^{m G F P}$ reporter mouse line (Hippenmeyer et al. 2005) to allow histological and single-cell RT-PCR analyses with selectivity for the TH-Cre-expressing cells, thus producing the Vglut $2^{f f f ; T a u-m G F P}$ mouse, which was subsequently crossed with the TH-Cre mice to produce Vglut $2^{f / f ; T H-C r e ; T a u-m G F P}$ (cKO-Cre-GFP) and Vglut $2^{f /+; T H-C r e ; T a u-m G F P}$ littermate controls (Ctrl-Cre-GFP). The Tau ${ }^{m G F P}$ Cre-reporter mouse allows visualization of Cre-expressing cell nuclei by detection of $\beta$-galactosidase ( $\beta$-gal) protein and projections of the corresponding cells by green fluorescent protein (GFP). Littermate control mice were used in all experiments to ensure that any aberrant phenotypes were specifically dependent on the deletion of Vglut2 expression in TH-Cre-expressing neurons. Further, the observer was blind to the genotype of the mice until the final analysis stage.

In situ hybridization and immunohistochemistry

\section{Tissue preparation}

Animals were mated overnight for production of cKO-CreGFP and Ctrl-Cre-GFP offspring, and females were checked for a vaginal plug the following morning.
Embryos were collected at embryonic (E) day 12 and 14. In the morning of E19, pups were born and staged as P0. For dissection of embryos, pregnant females were sacrificed by cervical dislocation and embryos were removed. For collection of adult brains, mice were sacrificed by cervical dislocation and brains removed. Amniotic sac (from embryos) and tails (from pups) were collected for genotyping according to protocols previously described (Wallén-Mackenzie et al. 2006). The tissue was fixed in zinc formalin (Richard-Allan Scientific, Kalamazoo, MI) for 18-24 h at room temperature before dehydration and paraffin infusion (Tissue Tek vacuum infiltration processor; Miles Scientific, Elkhart, IN). Sections (7 $\mu \mathrm{m}$ thick) were cut on a Microm microtome, attached to Superfrost slides (Menzel-Gläser, Braunschweig, Germany) and stored at $4{ }^{\circ} \mathrm{C}$ until usage. Slides were then deparaffinized in X-tra solve (MediteHistotechnic, Burgdorf, Germany) and rehydrated in ethanol/water before subsequent treatments.

\section{In situ hybridization histochemistry}

For paraffin in situ hybridization histochemistry, rehydrated paraffin sections were fixed for $10 \mathrm{~min}$ in $4 \%$ formaldehyde, washed in phosphate-buffered saline (PBS), and treated with proteinase $\mathrm{K}$ (Sigma; $27 \mu \mathrm{g} / \mathrm{ml}$ diluted in $10 \mathrm{mM}$ Tris-HCl/1 mM EDTA, $\mathrm{pH}$ 8.0) for $5 \mathrm{~min}$. After refixation and washes in $\mathrm{PBS}$, the slides were acetylated for $10 \mathrm{~min}$ in a mixture of $1.3 \%$ triethanolamine (Sigma), $0.2 \%$ acetic anhydride (Fluka, Neu-Ulm, Germany), and $0.06 \% \mathrm{HCl}$ diluted in water. Slides were then incubated for $30 \mathrm{~min}$ in PBS containing $1 \%$ Triton X-100 (Sigma). After subsequent washes in PBS, slides were prehybridized for $2-5 \mathrm{~h}$ in hybridization solution without probe [50\% formamide (Fluka), $5 \times$ saline-sodium citrate (SSC), $5 \times$ Denhardt's, $250 \mu \mathrm{g} / \mathrm{ml}$ yeast transfer RNA (Sigma) and $500 \mu \mathrm{g} / \mathrm{ml}$ sheared salmon sperm DNA (Ambion, Austin, TX, USA) diluted in water]. The probe for Vglut2 (covering nucleotides $1,616-2,203$ ) was diluted to $0.1-1 \mu \mathrm{g} / \mathrm{ml}$ in hybridization solution and heated to $80{ }^{\circ} \mathrm{C}$. Sections were then hybridized with $100 \mu$ of hybridization solution for $16 \mathrm{~h}$ at $70{ }^{\circ} \mathrm{C}$. The next day, slides were dipped in prewarmed $5 \times \mathrm{SSC}$, transferred to $0.2 \times \mathrm{SSC}$, and incubated for $2 \mathrm{~h}$ at $70{ }^{\circ} \mathrm{C}$. After one wash in $0.2 \times \mathrm{SSC}$ at room temperature and one wash in $\mathrm{B} 1$ solution $(0.1 \mathrm{M}$ Tris- $\mathrm{HCl}, \mathrm{pH} 7.5$, and $0.15 \mathrm{M} \mathrm{NaCl}$ ), sections were immuno-blocked with $10 \%$ foetal calf serum in B1, and then incubated overnight at $4{ }^{\circ} \mathrm{C}$ with alkaline phosphatase-conjugated anti-digoxigenin Fab fragments (Roche, Mannheim, Germany) diluted 1:5,000 in B1 containing $1 \%$ foetal calf serum. The following day, slides were washed in B1, equilibrated in B3 (0.1 M Tris-HCl, pH 9.5, $0.1 \mathrm{M} \mathrm{NaCl}, 50 \mathrm{mM} \mathrm{MgCl} 2)$, and colour developed in a $10 \%$ polyvinyl alcohol (Sigma) solution also containing 
$100 \mathrm{mM}$ Tris-HCl, pH 9.5, $100 \mathrm{mM} \mathrm{NaCl}, 5 \mathrm{mM} \mathrm{MgCl} 2$, $0.17 \%$ nitroblue tetrazolium (Roche), $0.17 \%$ 5-bromo-4chloro-3-indolyl phosphate (Roche), and $1 \mathrm{mM}$ levamisole (Sigma). Staining was sufficient after 6-24 h, whereupon slides were washed in PBS and incubated overnight with primary mouse TH (Chemicon) antibody and processed as described below (omitting the boiling procedure).

\section{Immunofluorescence histochemistry}

For immunofluorescence histochemistry, rehydrated paraffin sections were boiled (this step was omitted in experiments of combined in situ hybridization and immunofluorescence) for $10 \mathrm{~min}$ in $0.1 \mathrm{M}$ citric acid (VWR International, Leicestershire, UK), pH 6.0, left to cool for 20-30 min, washed in PBS, and incubated with primary mouse $\mathrm{TH}$ (Chemicon), rabbit $\beta$-gal (ICN/Cappel), chicken GFP (Abcam), chicken and guinea pig VGLUT2 [own production based on peptide sequences described in (Hioki et al. 2003)] via Innovagen, Lund, Sweden), rat Nestin (Dev Studies Hybridoma Bank), rabbit vesicular inhibitory amino acid transporter (VIAAT; gift from Prof Bruno Gasnier (McIntire et al. 1997; Sagne et al. 1997), mouse alpha-Internexin (Chemicon), mouse $\beta$-III-Tubulin (TUJ1; Chemicon), rabbit Synapsin (Chemicon), respectively, in PBS with $0.3 \%$ Triton $\mathrm{X}-100$ at room temperature overnight. The following day, slides were washed in PBS and incubated with Alexa fluorescent secondary antibodies (Invitrogen, San Diego, CA) diluted 1:200 in PBS with $0.3 \%$ Triton X-100 and $10 \%$ goat serum for $2 \mathrm{~h}$ at room temperature. Slides were

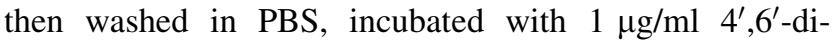
amidino-2-phenylindole (DAPI) (Sigma), washed again, and mounted. Images were captured on a Zeiss LSM 510 Meta confocal microscope and analysed using Volocity software (Improvision).

\section{Combination of Vglut2 in situ hybridization and $\mathrm{TH}$ immunolabeling}

Coronal free-floating sections $(10,12$ or $16 \mu \mathrm{m}$ in thickness) were processed as described previously (Wang and Morales 2008). Sections were incubated for $10 \mathrm{~min}$ in phosphate buffer (PB) containing $0.5 \%$ Triton X-100, rinsed $2 \times 5 \mathrm{~min}$ with $\mathrm{PB}$, treated with $0.2 \mathrm{~N} \mathrm{HCl}$ for $10 \mathrm{~min}$, rinsed $2 \times 5 \mathrm{~min}$ with $\mathrm{PB}$ and then acetylated in $0.25 \%$ acetic anhydride in $0.1 \mathrm{M}$ triethanolamine, $\mathrm{pH} 8.0$ for $10 \mathrm{~min}$. Sections were rinsed $2 \times 5 \mathrm{~min}$ with $\mathrm{PB}$, postfixed with $4 \%$ paraformaldehyde (PFA) for $10 \mathrm{~min}$. Prior to hybridization and after a final rinse with $\mathrm{PB}$, the freefloating sections were incubated in hybridization buffer (50\% formamide; $10 \%$ dextran sulfate; $5 \times$ Denhardt's solution; $0.62 \mathrm{M} \mathrm{NaCl}$; $50 \mathrm{mM}$ DTT; $10 \mathrm{mM}$ EDTA;
20 mM PIPES, pH 6.8; $0.2 \%$ SDS; $250 \mu \mathrm{g} / \mathrm{ml}$ salmon sperm DNA; $250 \mu \mathrm{g} / \mathrm{ml}$ tRNA) for $2 \mathrm{~h}$ at $55^{\circ} \mathrm{C}$. Sections collected on glass slides were dehydrated through a series of graded ethanol (50, 70 and $95 \%, 5$ min for each concentration). Sections were hybridized for $16 \mathrm{~h}$ at $55^{\circ} \mathrm{C}$ in hybridization buffer containing $\left[{ }^{35} \mathrm{~S}\right]$ - and $\left[{ }^{33} \mathrm{P}\right]$-labelled single-stranded antisense or sense Vglut2 (nucleotides 317-2,357, Accession \# NM_053427) probes at $10^{7} \mathrm{cpm} /$ ml. Sections were treated with $4 \mu \mathrm{g} / \mathrm{ml}$ RNase A at $37{ }^{\circ} \mathrm{C}$ for $1 \mathrm{~h}$, washed with $1 \times \mathrm{SSC}, 50 \%$ formamide at $55^{\circ} \mathrm{C}$ for $1 \mathrm{~h}$, and with $0.1 \times \mathrm{SSC}$ at $68^{\circ} \mathrm{C}$ for $1 \mathrm{~h}$. After the last SSC wash, sections were rinsed with $\mathrm{PB}$ and incubated for $1 \mathrm{~h}$ in PBS supplemented with $4 \%$ bovine serum albumin and $0.3 \%$ Triton X-100. This was followed by overnight incubation at $4{ }^{\circ} \mathrm{C}$ with an anti-TH mouse monoclonal antibody (1:500, MAB 318, Millipore, Billerica, MA) for which specificity has been documented (Tagliaferro and Morales 2008). After rinsing $3 \times 10 \mathrm{~min}$ in PB, sections were processed with an $\mathrm{ABC}$ kit (Vector Laboratories, Burlingame, CA). The material was incubated for $1 \mathrm{~h}$ at RT in a 1:200 dilution of the biotinylated secondary antibody, rinsed with PB, and incubated with avidin-biotinylated horseradish peroxidase for $1 \mathrm{~h}$. Sections were rinsed and the peroxidase reaction was then developed with $0.05 \%$ 3, 3-diaminobenzidine-4 $\mathrm{HCl}$ (DAB) and $0.03 \%$ hydrogen peroxide. Free-floating sections were mounted on coated slides. Slides were dipped in Ilford K.5 nuclear tract emulsion (Polysciences, Inc., Warrington; 1:1 dilution in double distilled water) and exposed in the dark at $4{ }^{\circ} \mathrm{C}$ for 4 weeks prior to development. Slides processed for fluorescent and bright-field histochemistry were analysed using an Olympus (Tokyo, Japan) microscope with an Optigrid system (Thales, Fairport, NY) and by confocal microscopy using the Zeiss (Oberkochen, Germany) LSM 510 META system. Images were captured using Volocity software (Improvision, Lexington, MA) and captured images were auto-levelled using Adobe Photoshop software. For cell counting within the IF and RLi areas, an observer blind to the genotype of the mice ( $1 \mathrm{cKO}$ and 1 control) counted TH-expressing, Vglut2-expressing and TH/Vglut2-expressing cells in $11 \mathrm{cKO}$ and 9 control sections.

\section{Single-cell RT-PCR}

Brains were obtained from P1 cKO-Cre-GFP and Ctrl-CreGFPmice following decapitation. A $1 \mathrm{~mm}$ thick coronal slice, which contained the mesencephalon was prepared under fluorescent microscope. Excess tissue was removed until only the substantia nigra pars compacta $(\mathrm{SNc})$ and A10 areas, visualized by TH-Cre-driven GFP fluorescence, remained. The tissue was collected in ice-cold dissociation solution (90 mM Na $2 \mathrm{SO}_{4}, 30 \mathrm{mM} \mathrm{K}_{2} \mathrm{SO}_{4}, 5.8 \mathrm{mM} \mathrm{MgCl}_{2}$, $0.25 \mathrm{mM} \mathrm{CaCl}_{2}, 10 \mathrm{mM}$ HEPES, $20 \mathrm{mM}$ glucose, and 
$0.001 \%$ phenol red, $\mathrm{pH}$ 7.4) then digested with papain for $20 \mathrm{~min}$ at $37^{\circ} \mathrm{C}$ with agitation. The tissue was then triturated by several passages through glass pipettes of decreasing diameter to obtain a cell suspension (see inset in Fig. 8 for illustration of this procedure). The cells were then centrifuged through a differential gradient to eliminate dead cells and debris. Cells were plated on poly-L-lysinecoated coverslips and left to adhere for $30 \mathrm{~min}$ at $37{ }^{\circ} \mathrm{C}$. The coverslips were then washed with Krebs-Ringer buffer (KRB) (140 mM NaCl, $5 \mathrm{mM} \mathrm{KCl,} 2 \mathrm{mM} \mathrm{MgCl} 2,2 \mathrm{mM}$ $\mathrm{CaCl}_{2}, 10 \mathrm{mM}$ HEPES, $10 \mathrm{mM}$ glucose, $6 \mathrm{mM}$ sucrose, $\mathrm{pH}$ 7.35) to eliminate non-attached cells and in KRB during single cell collection. GFP-expressing cells were randomly collected to avoid a selection bias towards cells that express high levels of GFP. All cells were collected individually using autoclaved borosilicate patch pipettes under RNAse-free conditions; each cell was collected by applying light negative pressure to the pipette, no intracellular pipette solution was used. The content of each pipette was transferred into individual pre-chilled tubes containing a freshly prepared solution of $20 \mathrm{U}$ of RNase inhibitor and $8.3 \mathrm{mM}$ DTT, samples were frozen immediately on dry ice and stored at $-80{ }^{\circ} \mathrm{C}$ until use. The samples were thawed on ice and the RNA converted to cDNA by reverse transcription for $1 \mathrm{~h}$ using $0.5 \mathrm{mM}$ dNTPs mix, $1.25 \mu \mathrm{M}$ random primers, $40 \mathrm{U}$ of RNase inhibitor, $100 \mathrm{U}$ of M-MLV RT (Invitrogen), $50 \mathrm{mM}$ Tris- $\mathrm{HCl}, 75 \mathrm{mM} \mathrm{KCl}$ and $3 \mathrm{mM}$ $\mathrm{MgCl}_{2}, \mathrm{pH}$ 8.3. The RT enzyme was denatured and the cDNAs stored at $-80{ }^{\circ} \mathrm{C}$ until use. A first round of PCR was performed using $1.5 \mathrm{mM} \mathrm{MgCl}, 10 \mathrm{pmol}$ of each primer, $1.0 \mathrm{U}$ of platinum Taq-DNA polymerase (Invitrogen), $20 \mathrm{mM}$ Tris- $\mathrm{HCl}$ and $50 \mathrm{mM} \mathrm{KCl} \mathrm{pH} \mathrm{8.4.} \mathrm{Thermal}$ cycles consisted of an initial denaturation step of $94{ }^{\circ} \mathrm{C}$ for $2 \mathrm{~min}$, followed by 35 cycles of $94{ }^{\circ} \mathrm{C}$ for $50 \mathrm{~s}, 55^{\circ} \mathrm{C}$ for $45 \mathrm{~s}$ and $72{ }^{\circ} \mathrm{C}$ for $45 \mathrm{~s}$. A second nested PCR was then performed as mentioned above using $10 \%$ of the first PCR reaction as template. All PCR products were resolved on $2.5 \%$ agarose gels. Primers were designed based upon sequences deposited in the GenBank database (www.ncbi. nlm.nih.gov/nucleotide). The Vglut2 primers were designed around exons 4, 5 and 6 to detect both the wildtype and the knockout allele. $T H$ and $D A T$ mRNA expressions were also investigated. The oligonucleotides used were Vglut2: first round sense 5-gccgctacatcatag ccatc- 3 and antisense 5 -gctctctccaatgctctcctc-3, nested sense 5 -acatggtcaacaacagcactatc- $\mathbf{3}$ and antisense 5 -ataag acaccagaagccagaaca- 3 ; TH: first round sense 5 -gttctcaa cctgctcttctcctt- $\mathbf{3}$ and antisense $\mathbf{5}$-ggtagcaatttcctccttgtgt- $\mathbf{3}$, nested sense 5-gtacaaaaccctcctcactgtctc- 3 and antisense 5-cttgtattggaaggcaatctctg-3; DAT: first round sense 5-ttcact gtcatcctcatctctttc- -3 and antisense 5 -gaagctcgtcaggga gttaatg- $\mathbf{3}$, nested sense 5 -gtattttgagcgtggtgtgct- $\mathbf{3}$ and antisense 5 -gatccacacagatgcctcac-3.
Behavioural studies

Spontaneous and amphetamine-induced locomotor activity

To assess spontaneous and amphetamine-induced activity, mice were placed in automated activity chambers, socalled Locoboxes, consisting of a plastic cage $(55 \times 55 \times 22 \mathrm{~cm})$ inside a ventilated and illuminated $(10$ lux) cabinet (Locobox, KungsbackaMät- ochReglerteknik $\mathrm{AB})$ in which activity was recorded as the following parameters: corner time, horizontal locomotion, vertical locomotion (rearing) and peripheral activity. After $30 \mathrm{~min}$ of baseline recording, mice received an intraperitoneal injection of saline and their locomotive activity was recorded for a further $90 \mathrm{~min}$. To assess their drug-induced behaviour, 2-3 days after the saline injection, the same procedure was followed, but the mice were instead given an intraperitoneal injection of $1.5 \mathrm{mg} / \mathrm{kg}$ amphetamine. Data analysis was performed using the GraphPad Prism software (GraphPad Software Inc., La Jolla, USA).

\section{The radial arm maze}

The radial arm maze is a hippocampus-dependent task used to record spatial working memory (WM), in which the ability of the mouse to remember the location of foodbaited versus unbaited arms is measured (Meck et al. 1984). Spatial memory performance was examined in 24 cKO mice and littermate controls, all males using an eightarmed radial maze (see Fig. 5 for illustration of the radial maze and the parameters scored). The maze, elevated $45 \mathrm{~cm}$ above the floor, consisted of eight open arms $(60 \mathrm{~cm}$ long and $12.5 \mathrm{~cm}$ wide, surrounded by inclining walls at a height of $13 \mathrm{~cm}$ at the centre and $3 \mathrm{~cm}$ at the end of the maze arms) radiating from a central compartment $(30 \mathrm{~cm}$ in diameter). A podium $(10 \times 4 \mathrm{~cm})$ with a recessed food plate (diameter $3 \mathrm{~cm}$ ) was fixed at $1.5 \mathrm{~cm}$ from the end of each of the maze arms. Three days prior to the beginning of the experiment, the mice were schedule-fed for $6 \mathrm{~h} / \mathrm{day}$, which was reduced to $2 \mathrm{~h} /$ day at the start of the behavioural studies. Four of the eight arms were baited with the preferred food, R6-38, consisting of a high content of theobroma cacao. For the acquisition period, the animals were placed individually in the centre of the maze once each day for 5 days. The animals were allowed to perform for 10 min on the first trial day and thereafter the animals were allowed to remain in the apparatus until all reinforcements were obtained or until $10 \mathrm{~min}$ had elapsed, whichever occurred first. The same four arms were baited with a small piece of reinforcement food pellet each day. Nineteen days after the last acquisition session a retention test was performed. The same arms were baited and the mice again the same procedure was followed. The mice were manually 
scored for performance during the trial time. For scoring, an entry half way into an arm was defined as an arm entry. For each trial, a reference memory error (RME) was defined as a visit into an unbaited or incorrect arm. A working memory error (WME) was defined as a re-entry into an arm in which the reward was already obtained during the session. The total number of entries into each arm and the percentage of correct responses were also scored. Results were analysed using StatView 5.0 for Windows. A $2 \times 2 \times 6$ (genotype $\times$ sex $\times$ trial days) two-way repeated-measures ANOVA was used to assess RME, WME, total number of arm entries and the percentage of correct responses obtained during trial period. Test day was analysed by Student's $t$ test.

\section{High-pressure liquid chromatography (HPLC) with electrochemical detection}

Brains were obtained from $\mathrm{cKO}$ and littermate control mice ( $7 \mathrm{Ctrl}, 7 \mathrm{cKO}$ ) following euthanasia by cervical dislocation. The brains were put in a $1 \mathrm{~mm}$ coronal mouse brain matrix (Ted Pella Inc, Redding, CA, USA) kept on ice and sliced. The olfactory bulb, a combination of the substantia nigra and the ventral tegmental area (VTA/SNc), hypothalamus, nucleus accumbens (NAcc), caudate putamen $(\mathrm{CaPu})$, prefrontal cortex (PFC), amygdala and hippocampus were excised from the slices, weighed and stored at $-80{ }^{\circ} \mathrm{C}$. The tissue was subsequently homogenized by sonification in $0.1 \mathrm{M}$ perchloric acid solution $(50 \mathrm{mg}$ (1.6 mM) glutathione; $1.5 \mathrm{~g}(149 \mathrm{mM}) 70 \%$ PCA; $100 \mathrm{ml}$ $\mathrm{H}_{2} \mathrm{O}$ ). The homogenates were centrifuged at $4{ }^{\circ} \mathrm{C}$ for $15 \mathrm{~min}$ at $12,000 \times \mathrm{g}$ and the supernatant recovered for analysis of DA and its metabolites 3,4-dihydroxyphenylacetic acid (DOPAC) and homovanillic acid (HVA) content by HPLC. $40-50 \mu \mathrm{l}$ of the supernatant was injected onto the HPLC column with the current set to $50 \mathrm{nA}$ for all samples. A mobile phase (containing $55 \mathrm{mM}$ sodium acetate, $0.01 \mathrm{mM}$ EDTA, $1.16 \mathrm{mM}$ 1-octanesulfonic acid sodium salt, $10 \%$ methanol, $\mathrm{pH} 4$ ) was used to separate the analytes. Chromatograms were captured using the Azure program (Kromatek, Essex, England) and the pmol values of the peaks were calculated from a standard curve for each DA, DOPAC and HVA. All statistical analyses of the data were performed using GraphPad Prism 5.0 software. Outliers were identified using the Grubbs test and excluded from the analysis. The concentration of each metabolite was compared between the $\mathrm{cKO}$ and littermate control mice using the Mann-Whitney $U$ test.

\section{Electrophysiology}

In vitro local field potential (LFP) recordings from hippocampus slices were performed as previously described
(Leao et al. 2009). Following decapitation under isoflurane anaesthesia, brains of P18-P25 cKO and littermate control mice were removed from the skull and placed in ice-cold high-sucrose artificial cerebrospinal fluid (ACSF) (in $\mathrm{mM}$ : $\mathrm{KCl}, 2.49 ; \mathrm{NaH}_{2} \mathrm{PO}_{4}, 1.43 ; \mathrm{NaHCO}_{3}, 26$; glucose, 10; sucrose, 252; $\left.\mathrm{CaCl}_{2}, 1 ; \mathrm{MgCl}_{2}, 4\right)$. A vibratome (VT1000, Leica Microsystems) was used to obtain horizontal hippocampal slices that were moved to a submerged recording chamber containing ACSF (in $\mathrm{mM}: \mathrm{NaCl}, 124 ; \mathrm{KCl}, 3.5$; $\mathrm{NaH}_{2} \mathrm{PO}_{4}, 1.25 ; \mathrm{MgCl}_{2}, 1.5 ; \mathrm{CaCl}_{2}, 1.5 ; \mathrm{NaHCO}_{3}, 30$; glucose, 10), constantly bubbled with $95 \% \mathrm{O}_{2}$ and $5 \%$ $\mathrm{CO}_{2}$ and kept at $35^{\circ} \mathrm{C}$ for $1 \mathrm{~h}$ then maintained at room temperature. For LFP recordings, slices were transferred to an interface-type chamber and kept at $35^{\circ} \mathrm{C}$ (Zelano et al. 2013). A recording glass pipette filled with ACSF was placed in the stratum radiatum of CA3. LFP signals were amplified $100 \times$ using custom-made amplifier (John Curtin School of Medical Research, Australian National University), low-pass filtered at $3 \mathrm{kHz}$ and digitized at $10 \mathrm{kHz}$ by a National Instruments DAQ card. Data were analysed using Matlab (Mathoworks).

\section{Results}

Vglut2 expression in TH and non-TH-expressing cells in the embryonic VTA area

We have previously shown that Vglut2 is prominently expressed in the subventricular zone in several cortical, subcortical and brainstem structures, including in $\mathrm{TH}$ expressing neurons in the ventral midbrain, of the mouse already at midgestation (Birgner et al. 2010). To analyse if Vglut2 gene expression at these early developmental stages results in protein products, we analysed localization of the VGLUT2 protein in combination with a range of various molecular markers by immunohistochemistry (IHC). Ample VGLUT2 protein was found in the di-, mes- and metencephalon of the developing mouse brain already at E12, detected in the distinct, dotted appearance of presynaptic structures where it colocalised with the presynaptic marker Synapsin (Fig. 1a, representative example). VGLUT2 protein did not colocalize with Nestin, a marker for dividing neural progenitor cells (Lendahl et al. 1990) (Fig. 1b), but was detected in elongated structures resembling fibre bundles, where it showed some, but not complete colocalization with alpha-Internexin (Fig. 1c), a class IV intermediate filament protein commonly used as a marker for subclasses of neurons and the general neuronal fibre marker beta-III-Tubulin (TUJ1) (Fig. 1d). These fibre structures are usually not observed when analysing VGLUT2 protein immunoreactivity in the adult brain, where it is exclusively presynaptic and vesicular, 
Fig. 1 Immunohistochemical and in situ hybridization analysis on sagittal sections of the embryonal mouse brain. Immunofluorescent analysis of VGLUT2 (red) with cell nuclei labelled with DAPI (blue) at embryonic (E) day 12. Synaptic colocalization of VGLUT2 (red) and Synapsin (green) (a); Nestin-expressing neuronal progenitors (green) interspersed with VGLUT2 (red) (b); localization of VGLUT2 (red) within and parallel to fibrous structures immunoreactive for neuronal marker alphaInternexin (a-Internexin; green) (c left and right); localization of vesicular VGLUT2 (red dots) within neuronal fibre bundles labelled by $\beta$-III-Tubulin (Tuj1; green) (d); overview (E15) of ventral midbrain (VM) to visualize the area above mesencephalic flexure (MF) and TH-positive (green) neurons with projections in median forebrain bundle (MFB) to striatum (e), dotted square marks the area of sections shown in f, g; VGLUT2positive fibres (note, green) in the VM above the MF, no colocalization with the marker for inhibitory neurons, VIAAT (red) (f); VGLUT2-positive fibres (red) in VM area of THpositive neurons (green) (g);

(h) in situ hybridization combined with immunohistochemistry of Vglut2 mRNA (black) and TH protein (green) in the VM.Cells positive for both Vglut2 (black) and TH (green) marked with single asterisk cells positive for Vglut2 but not TH marked with hash
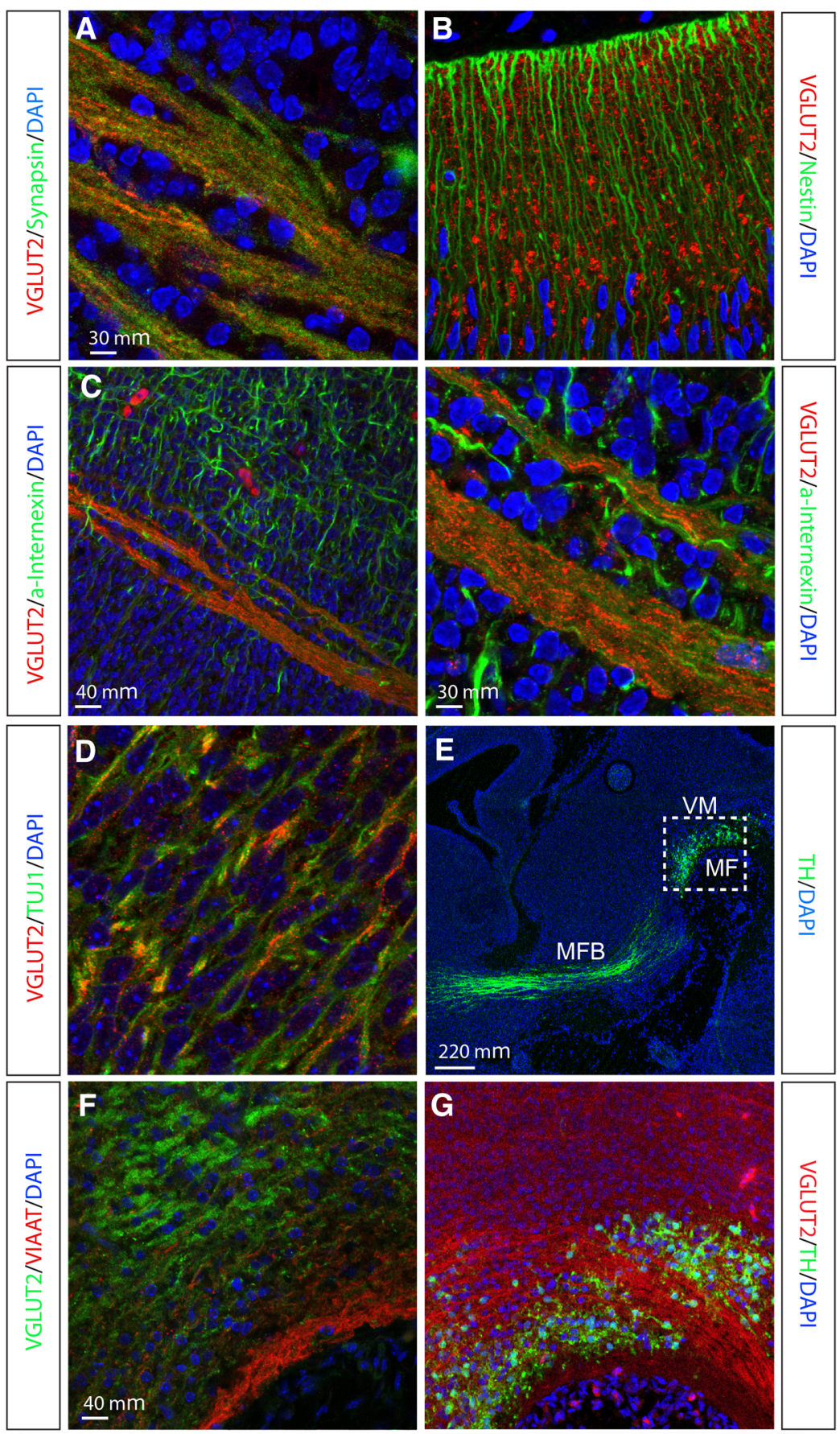

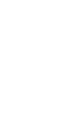


suggesting that VGLUT2 is present in the embryo already during the establishment of the developing axonal structures. When analysing the ventral midbrain (Fig. 1e for localization of area), VGLUT2 was found not to colocalize with VIAAT, a molecular marker for inhibitory neurons (Fig. 1f). $T H$-expressing neurons were found intermingled with VGLUT2-positive fibres, suggesting ample glutamatergic afferent input into this area (Fig. 1g). With the reports of a "Glu-only" neuronal population in the adult VTA (Hnasko et al. 2012; Kawano et al. 2006; Li et al. 2013; Yamaguchi et al. 2007), we wished to assess Vglut2 expression in the ventral mesencephalic flexure where VTA and SNc neurons form (Wang et al. 1995; Ye et al. 1998). Vglut2 in situ hybridization analysis at E12 combined with IHC for TH showed a mixture of cells expressing both Vglut2 and TH ("TH-Vglut2"), cells expressing Vglut2 but not TH ("Vglut2-only"), and cells expressing $T H$ but not Vglut2 ("TH-only") at all three embryonal stages examined (Fig. 1h for representative example, and Fig. 8 for illustration of these populations). Together, these analyses show that the Vglut2 gene is expressed from midgestation and onwards in the developing mouse brain, including the developing VTA area where it is found in both $\mathrm{TH}$-expressing and non- $\mathrm{TH}$-expressing cells.

TH-Cre activity detected in "TH-only", "TH-Vglut2" and "Vglut2-only" VTA neurons

The tau-mGFP floxed Cre-reporter (Hippenmeyer et al. 2005) was used to enable validation of Cre activity in the previously described TH-Cre knock-in mouse (Lindeberg et al. 2004) by IHC for $\beta$-galactosidase ( $\beta$-gal) and green fluorescent protein (GFP) in the same sections to detect TH-Cre-expressing cell nuclei ( $\beta$-gal) and projections(GFP) throughout the adult brain. By analysis of CtrlCre-GFP mice (see Materials and Methods for description), we could confirm the previous characterization of the THCre mice (Lindeberg et al. 2004) which, using the loxPSTOP-loxP-LacZ (Tsien et al. 1996), showed TH-Creactivity in all catecholaminergic cell groups, including the noradrenergic neurons of the A1, A2 and locus coeruleus groups, the adrenergic neurons of the $\mathrm{C} 1, \mathrm{C} 2$ and $\mathrm{C} 3$ groups in the medulla, in addition to the DA cell groups in the ventral midbrain (A8, A9, A10) and hypothalamus (A11-13) (data not shown). We could also confirm previous observations of TH-Cre activity in the dorsal root ganglia (Lagerström et al. 2010; Lindeberg et al. 2004), but in contrast to the previous characterization (Lindeberg et al. 2004), we did not detect TH-Cre activity, assessed by $\beta$-gal-IHC, in the cortex or hippocampus (data not shown). However, as described below, the hippocampus did contain GFP-immunoreactive fibres, confirming innervation from
Fig. 2 TH-Cre transgene analysis in the adult mouse brain via the tau-mGFP double Cre-reporter. Cell nuclei marked with DAPI (blue) (a). Projections from the ventral tegmental area and substantia nigra pars compacta (VTA/SNc) to the entire striatal area (left) via the median forebrain bundle (MFB) visualized by immunofluorescence for the green fluorescent protein (GFP), close-up of GFP fibres in the hippocampus (right) (a). Nuclear $\beta$-galactosidase ( $\beta$-gal; red) shows the position of cells in which TH-Cre activity has enabled $\beta$-gal expression; endogenous $\mathrm{TH}$ protein expression is indicated by $\mathrm{TH}$ immunoreactivity (green); co-localization ( $\beta$-gal (red) nuclei in centre of TH (green) cytoplasm) is mainly seen in medial (m) and lateral (1) VTA, less so in the medially located rostral linear nucleus (RLi) and Interfascicular nucleus (IF) where many cells show $\beta$-gal (red) only (b, c). Triple $\beta$-gal (red)/TH (blue)/GFP (green) immunofluorescence in RLi shows some $\beta$-gal/GFP-positive TH-Crereporting cells that immunopositive for TH (hash) and some that do not have TH (single asterisk) (d left and close-up to the right)

TH-Cre-expressing neurons located elsewhere (shown in Fig. 2b and also in Fig. 7a). We then focused our analyses on the ventral midbrain. By analysing GFP IHC in sagittal sections, we detected median forebrain bundle projections reaching from the VTA/SNc area to the dorsal and ventral striatum (Fig. 2a). Combined $\beta$-gal ("reporting" TH-Cre transgene activity) and $\mathrm{TH}$ (endogenous $\mathrm{TH}$ protein) IHC on coronal sections visualized the two markers in the A10 area (2C-D), with high-level magnification showing $\beta$-gal in the nuclei of TH-immunoreactive neurons (Fig. 2c-e). In addition, in the IF and RLi areas, where we (Fig. 3) and others (Hnasko et al. 2012; Li et al. 2013) detected Vglut2expressing cells that did not express endogenous $\mathrm{TH}$, several $\beta$-gal-positive cell nuclei were detected that lacked TH-immunoreactivity (Fig. 2b-d). Although somewhat surprising, these findings are in accordance with the original characterization of the TH-Cre transgene (Lindeberg et al. 2004)which found that due to early and transient expression from the $\mathrm{TH}$ promoter during development, the Cre transgene will be active early on in cells not expressing stable endogenous TH later in life (see Fig. 8 for illustration of the TH promoter activity). This seemingly ectopic Cre activity will give rise to early deletion of any floxed alleles present and which will remain gene targeted throughout their life, thereby providing a molecular mechanism for how adult A10 cells can be immunopositive for $\beta$-gal but not TH. Based on this finding, we hypothesized that mice expressing both TH-Cre and the floxed Vglut2 allele, i.e. Vglut $2^{f f ;}$;H-Cre+ mice, should have Vglut2 gene targeted in both "TH-Vglut2" cells and in "Vglut2-only" cells.

Vglut2 mRNA in the adult VTA area verified in $\mathrm{TH}-$ and non- $\mathrm{TH}$-expressing cells

Previous studies have identified highest ventral midbrain Vglut2 expression in DA neurons of the medial A10 area, including the IF and RLi (see Fig. 3a for illustration) of the 

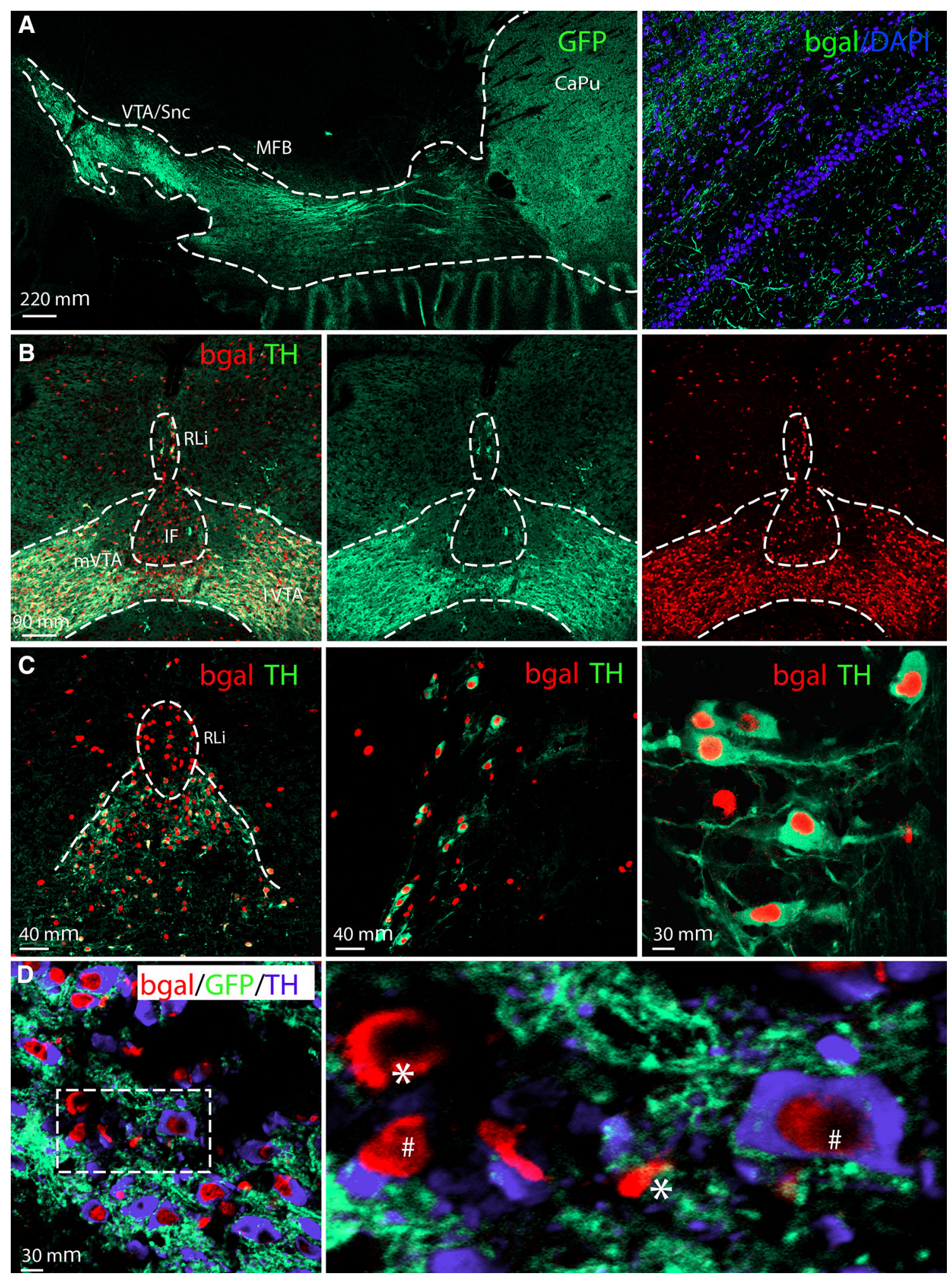

adult mouse and rat, intermingled with Vglut2-only expressing cells (Hnasko et al. 2012; Li et al. 2013; Yamaguchi et al. 2007). Based on these studies, we addressed Vglut2 expression in the ventral midbrain of the adult mouse of C57/BL6-Sv129 mixed genetic background and could confirm these previous reports (Hnasko et al. 

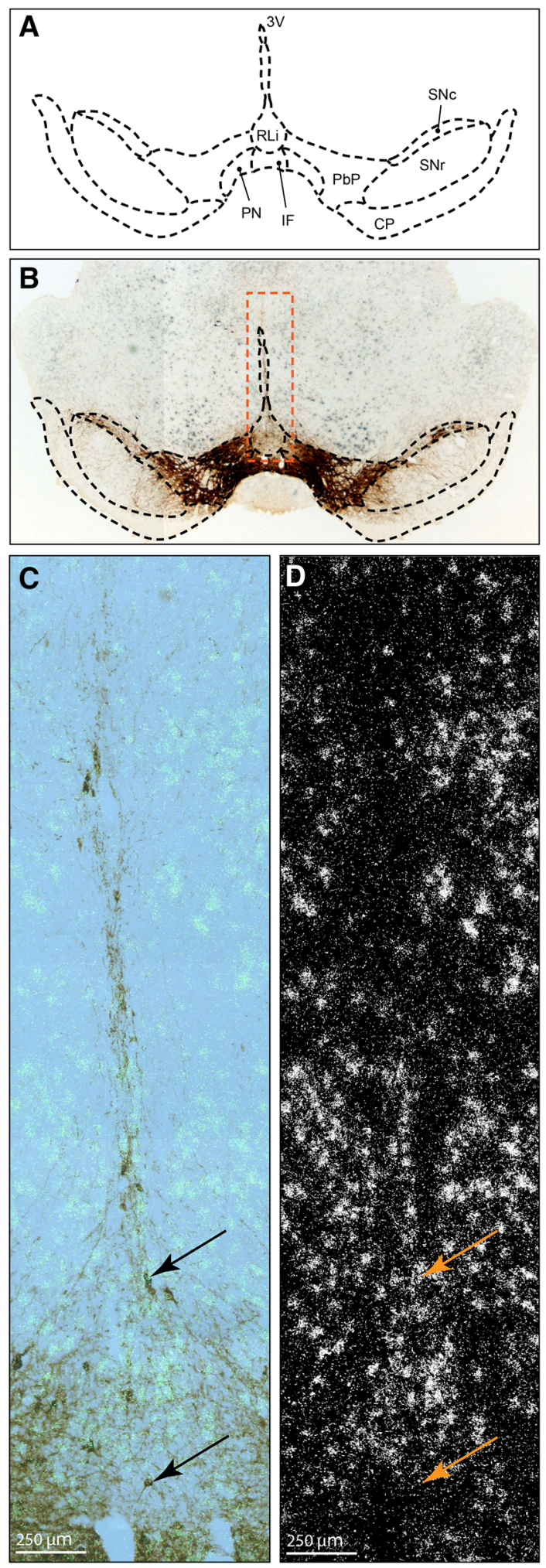

2012; Li et al. 2013; Yamaguchi et al. 2007). Vglut2 in situ hybridization combined with IHC for $\mathrm{TH}$ showed a mixture of cells expressing both Vglut2 and TH ("TH-Vglut2"), cells expressing Vglut2 but not $T H$ ("Vglut2-only"), and
Fig. 3 Localization of TH protein and Vglut2 mRNA by combined immunohistochemistry and in situ hybridization in coronal section of the adult mouse midbrain. Representative section at Bregma -3.16 . Illustration of anatomically distinct A10 areas, including the rostral linear nucleus of the raphé nuclei (RLi); paranigral nucleus (PN); interfascicular nucleus (IF); parabrachial pigmented nucleus (PbP); also marked is the substantia nigra pars compacta $(\mathrm{SNc})$; substantia nigra pars reticulata $(\mathrm{SNr})$. The cerebral peduncle $(\mathrm{CP})$ and third ventricle $(3 \mathrm{~V})$ were added as landmarks a; Overview of ventral midbrain showing Vglut2 mRNA broadly dispersed (grey) and THimmunoreactivity (brown) in $\mathrm{A} 10$ and $\mathrm{SNc}$ areas, with the above outlined structures as overlay (black dotted outline) and indicating the area of the close-ups below (orange dotted line) (b). Close-up images of the RLi and IF as indicated in B (orange outline) showing THimmunoreactivity (brown) and Vglut2 mRNA (light green) (c) and Vglut2 mRNA detected as silver grains (d). Arrows denote the same neurons in both panels; the upper arrow indicating a neuron positive for both $\mathrm{TH}$ and Vglut2, the lower arrow indicating a neuron positive for TH only

cells expressing $T H$ but not Vglut2 ("TH-only", presumably classical DA neurons) in the adult A10 area (Fig. 3bd). We next counted the number of $T H$-expressing (Mean/ SEM IF: Ctrl 33.6/8.6; cKO 34.3/10.0, RLi: Ctrl 10.9/4.8; cKO 5.1;1.2), Vglut2-expressing (Mean/SEM IF: Ctrl 8.3/ 3.4; cKO 4.1/1.1, RLi: Ctrl 29.0/8.6; $c K O ~ 16.5 / 3.3)$ and TH/Vglut2-expressing (Mean/SEM IF: Ctrl 0.3/0.2; cKO 0.3/0.1, RLi: Ctrl 1.8/0.5; $c K O 2 / 1.4)$ cells, respectively, in the IF and RLi areas of control (9 sections) and cKO (11 sections) mice in the Vglut $2^{f f f: T H-C r e}$ mouse line, but due to loss of material failed to reach a statistically relevant evaluation.

The TH-Cre transgene mediates deletion in "TH-Vglut2" and "Vglut2-only" neurons

To further analyse gene expression in TH-Cre-active cells, we turned to single-cell RT-PCR experiments in freshly dissociated GFP-positive cells derived from the dissected VTA/SNc area using Vglut2 primers designed to distinguish between the wildtype and knockout alleles (Fig. 4a). Sixty GFP-expressing cells were collected and prepared from P1 Ctrl-Cre-GFP and cKO-Cre-GFP mice, respectively (Fig. 8 for illustration). As expected, none of the green cells picked from the Ctrl-Cre-GFP mice expressed the Vglut2 knockout allele, instead all 12 cells expressing Vglut 2 showed the wildtype allele (representative examples shown in Fig. 4b). In contrast, Vglut 2 expression in the cKO-Cre-GFP was represented almost exclusively by the knockout allele; in 28 out of 29 (97\%) Vglut2-expressing cells recombination had occurred leading to a deletion of Vglut2, thus verifying the conditional targeting of Vglut2 (representative examples shown in Fig. 4b). In addition, primers for endogenous TH and DAT expression were used to further characterize the GFP-expressing cells. Out of 60 cells, 48 cells $(80 \%)$ were found to be expressing 
Fig. 4 Targeting construct and single-cell RT-PCR analysis. a Illustration of the genomic DNA sequence showing the Vglut2 locus in a wildtype mouse (uppermost panel), followed by the mRNA generated from the wildtype (WT) floxed allele that has not seen TH-Cre activity (middle), and the mRNA of the conditional knockout allele generated after TH-Cre-activity has excised the DNA sequence between the LoxP $(\mathrm{P})$ sites (lower panel). The Vglut2 primers for RT-PCR analysis on single cell material were designed around exons 4 and 6 to detect both the wildtype and knockout (KO) allele, the primer annealing sites for nested RT-PCR are indicated below the transcript as follows: first round in middle panel, second round in lower panel. b Representative example of a gel picture showing final RT-PCR products in single cell material (derived from GFP fluorescent, dissected VTA/SNc P1 conditional knockout (cKO) and control brains, resp.);Vglut2 (WT allele $506 \mathrm{bp}$, uppermost band; $\mathrm{KO}$ allele $372 \mathrm{bp}$, lowermost band), $T H$ and DAT, all as indicated to the right of the picture
A

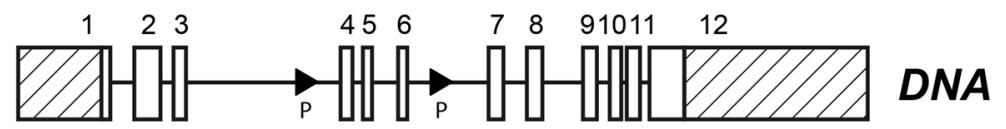
$\downarrow$ Ctrl (Vglut2 $\left.{ }^{\mathrm{f} / \mathrm{f}}\right)$

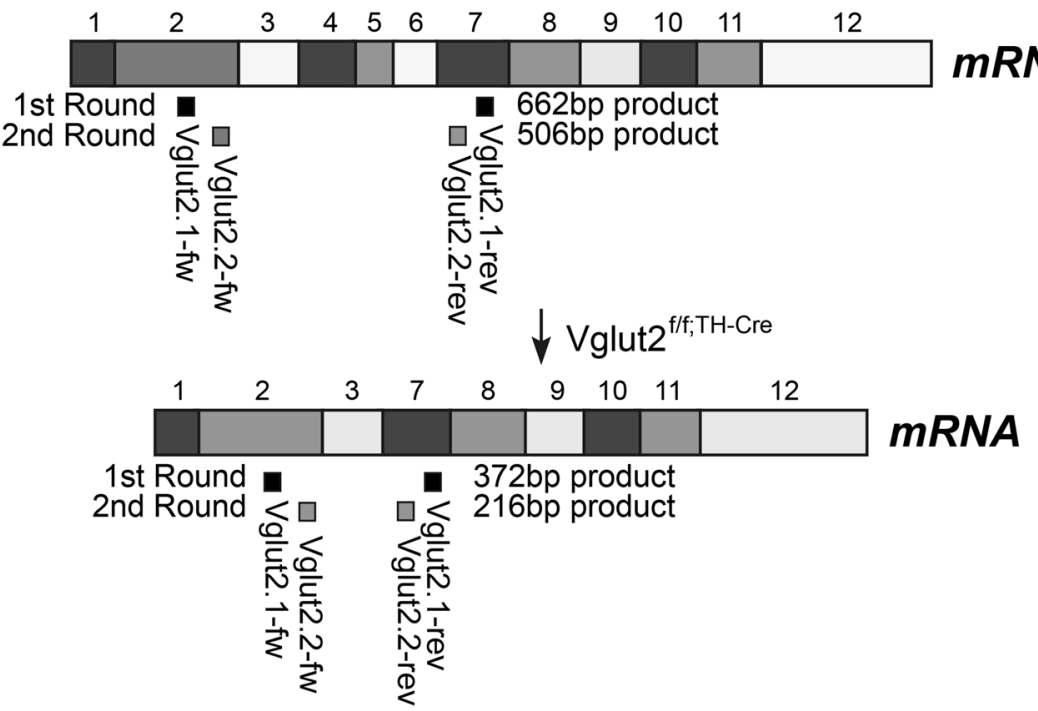

B

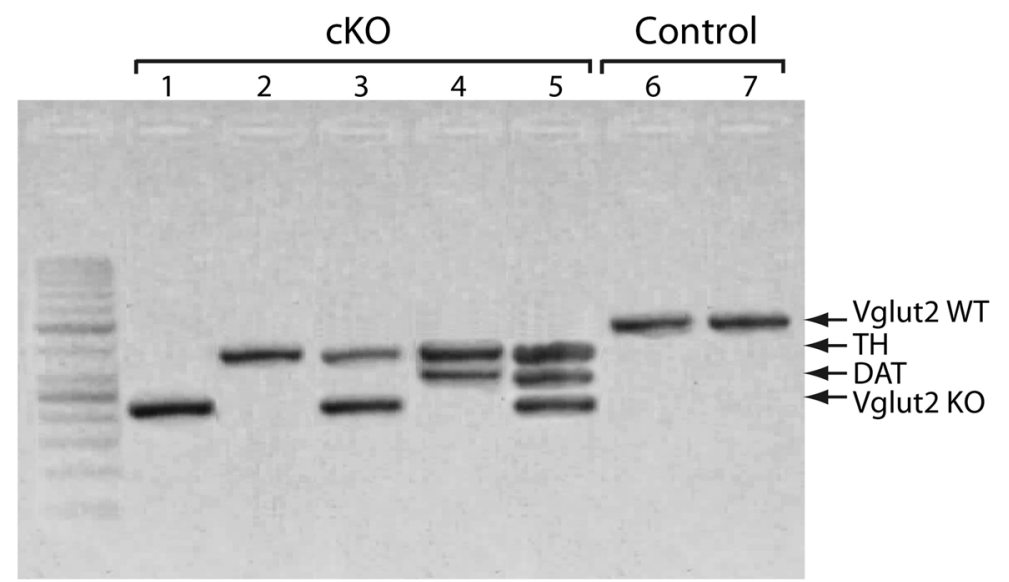

endogenous $T H$. Of these 48 cells, 13 cells $(22 \%$ of all cells) were coexpressing $T H$ and $D A T$ but did not contain Vglut2 (presumably classical DA neurons), 5 cells (8\% of all cells) were coexpressing $T H$, Vglut2 and DAT (possibly "TH-Vglut2 Class 1" neurons) and 18 cells (30\% of all cells) were found to be coexpressing $T H$ and Vglut2 (possibly " $\mathrm{TH}-$ Vglut2 Class 2" neurons). Further, six GFPexpressing cells $(10 \%)$ were also identified which expressed Vglut2 but not TH or DAT (possibly "Vglut2only" neurons). Representative examples of RT-PCR gene products are shown in Fig. 4b.

These results show that in cells expressing the TH-Cre transgene in the VTA/SNc area, as identified by green fluorescence, Vglut2 expression is found in "Vglut2-only" cells and in both populations of cells expressing TH, i.e. those expressing Vglut2 together with both $T H$ and $D A T$, and those expressing Vglut2 together with $T H$ only (See Fig. 8 for illustration). Vglut2 was identified as gene targeted (knocked out) within all three populations of VTAVGLUT2 neurons. Furthermore, the results indicate that recombination has occurred in nearly $100 \%$ of all picked GFP-positive neurons of the mesencephalon expressing Vglut2. This level of recombination is in accordance with our previous characterization showing gene targeting in $74 \%$ of the Vglut2-expressing cells of the dorsal root ganglia (DRG) in the same mouse line (Lagerström et al. 2010). In comparison, $82 \%$ of DAT-Cre-expressing cells which also expressed Vglut2 showed targeting of the Vglut2 allele in the previously characterized Vglut $2^{\text {fff;DAT-Cre }}$ mouse line (Birgner et al. 2010). 
Behavioural analysis reveals a normal amphetamine-induced activational response but decreased spatial memory

We have previously described that the Vglut $2^{f f ;} ; \mathrm{TH}-\mathrm{Cre} \mathrm{cKO}$ mice are fully viable but that TH-Cre activity in the DRG leads to an itch phenotype in some Vglut2 $2^{f f f ; H-C r e} \mathrm{CKO}$ mice at a late adult stage (Lagerström et al. 2010). This viable phenotype suggests absence of gross dysfunction in medullary cardiorespiratory functions, despite a presumed loss of Vglut2 expression in C1-3 adrenal cell groups. For behavioural phenotyping of the $\mathrm{Vglut} 2^{\mathrm{ff} ; \mathrm{TH}-\mathrm{Cre}} \mathrm{cKO}$ mice, we used mice around 7-8 weeks of age that did not show any itch-related phenotypes. To allow a comparison between the Vglut fff; TH-Cre and the Vglut2 $2^{f f ; \text { DAT-Cre }}$ mouse lines, which differ somewhat spatiotemporally in their targeting as described above, we performed the same behavioural tests of relevance to DA function as we previously performed on the Vglut $2^{f f f ; D A T-C r e}$ mouse line (Birgner et al. 2010) analysing reward-related function as well as affective and cognitive function, respectively. The tests included: psychostimulant-induced activational response, the forced swim test (FST), the elevated plus maze (EPM) and the radial maze. Spontaneous and amphetamine-induced activities were recorded in activity chambers, revealing no statistically significant differences between cKO and control mice, either pre- or post-injection, in either vertical or horizontal locomotion, or the time spent in peripheral versus central areas of the chamber (Fig. 5a, b and data not shown). Further, no differences between genotypes were observed in the FST in which the $\mathrm{cKO}$ and control mice spent equal time swimming in a twoday trial experiment (Supplementary Fig. 1A). In the EPM, no differences between genotypes were seen in time spent, or number of entries, in any area (Supplementary Fig. 1B). Analysis of the total number of entries during the entire trial showed no differences between genotypes, suggesting that the total activity of the mice is the same for both genotypes (Supplementary Fig. 1B).

The eight-armed radial maze (illustration Fig. 5c) was utilized to determine whether there was any impairment in hippocampus-dependent spatial memory (Meck et al. 1984) performance in the cKO mice. The overall performance of the mice in the maze task was determined by the percentage of correct responses. Both the cKO and the littermate control mice increased their efficiency throughout the trials $[F(1,100)=12.558, p<0.0001]$. However, cKO mice took significantly longer to acquire the task in comparison to the littermate controls $[F(1,20)=8.369$, $p=0.009$ ] (Fig. 5d). There was no difference in the retention (18 days post-acquisition) of the learned task between the two genotypes (Fig. 5d). Reference memory error (RME) and working memory error (WME) were also investigated in the task (Fig. 5e, f). There was a significant overall difference in spatial processing throughout the trial days for both RME $[F(5,100)=12,234, p<0.0001]$ and WME $[F(5,75)=3.645, p=0.0053]$. cKO mice made significantly more RMEs in comparison to the littermate control mice across the trial days $[F(1,20)=5.605$, $p=0.0281$ ] (Fig. 5e), whereas WMEs were not significantly different in the two groups $[F(1,15)=3.504$, $p=0.0809$ ] (Fig. 5f). No differences were seen between the two genotypes in either the RME or WME on day 23 (Fig. 5e, f).

Taken together, this data show that $\mathrm{Vglut} 2^{f f ;} ; \mathrm{TH}-\mathrm{Cre} \mathrm{CKO}$ mice lack alterations in depression-like and anxiety-like behaviour as measured by the FST and the EPM paradigm, respectively. These behavioural phenotypes mimic those of the Vglut fff;DAT-Cre cKO mice characterized previously (Birgner et al. 2010), as does the finding of normal levels of total activity, detected both in the activity chambers prior to injection of psychostimulant, and in the EPM. In contrast, Vglut ${ }^{f f f ; H-C r e} \mathrm{CKO}$ mice lack the altered response to the psychostimulant amphetamine, which is evident in the Vglut $2^{f f ; D A T-C r e}$ cKO mice, but show an impairment in the acquisition of the radial maze task and performed more spatial RMEs than control mice. Spatial memory functions are mediated by the hippocampus and were previously found normal in the Vglut $2^{f f ;}$ DAT-Cre $\mathrm{cKO}$ mice. Thus, the targeting of Vglut 2 expression by TH-Cre does not produce the identical phenotype as corresponding targeting by DAT-Cre, a finding likely reflected by the herein identified fact that TH-Cre and DAT-Cre differ quite substantially in their targeting of floxed Vglut2 cells.

HPLC analysis reveals altered DA levels in the hippocampus

The VGLUT2 protein has been suggested to play a role in DA transmission by affecting vesicular packaging of DA by a process termed "vesicular synergy", a concept which postulates that a VGLUT may work in synergy with another vesicular transporter, such as the monoamine transporter VMAT2, to increase the efficiency of this transporter (Gras et al. 2008). We and others have previously shown that loss of VGLUT2 in DA neurons in the Vglut $^{\text {fff;DAT-Cre }}$ mouse line leads to decreased DA release, possibly, but not conclusively, supporting the concept of vesicular synergy between VGLUT2 and VMAT2 (Alsiö et al. 2011; Hnasko et al. 2010). To assess if the targeted loss of VGLUT2 would affect DA levels in the Vglut $2^{f f ;}$ TH ${ }^{C r e}$ mouse line, HPLC was used to assess possible differences in the concentration of DA as well as its metabolites DOPAC and HVA in cKO and control mice. This analysis was carried out in a number of different brain regions, including the VTA/SNc area, the olfactory bulb and the 


\section{Amphetamine Challenge}

A

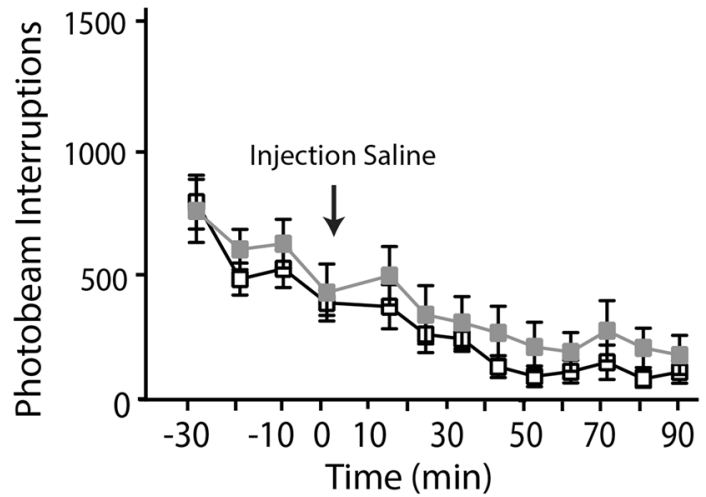

B

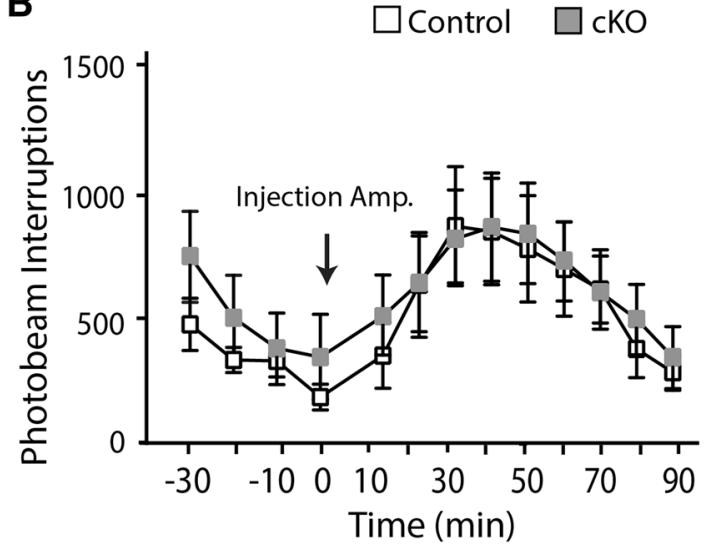

C

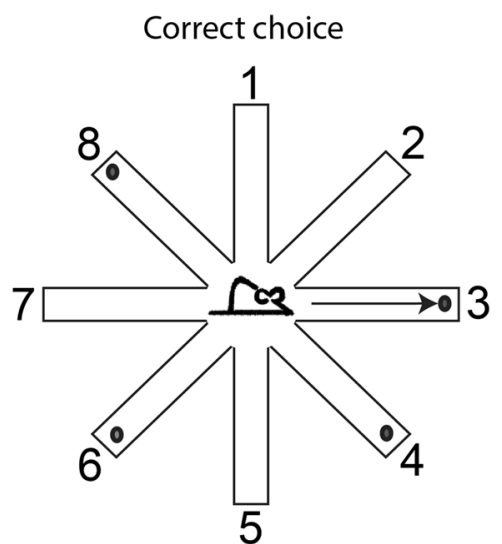

D

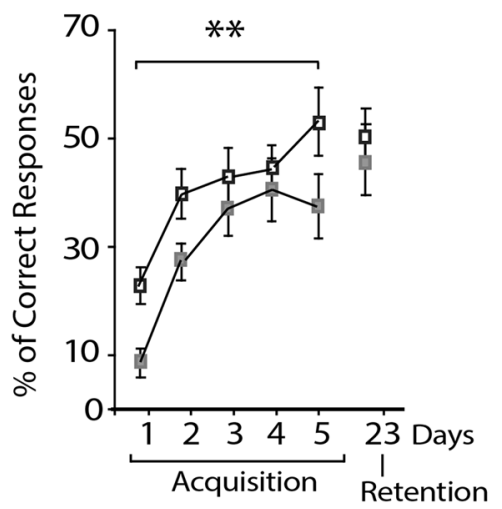

Radial Arm Maze

Reference Memory Error (RME)

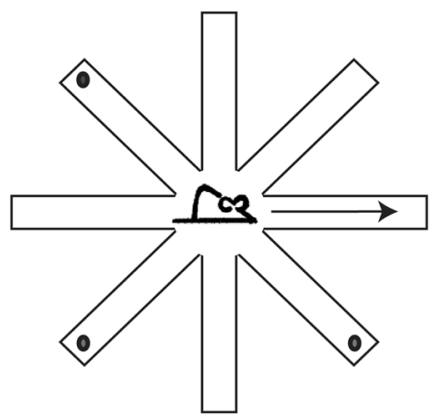

E

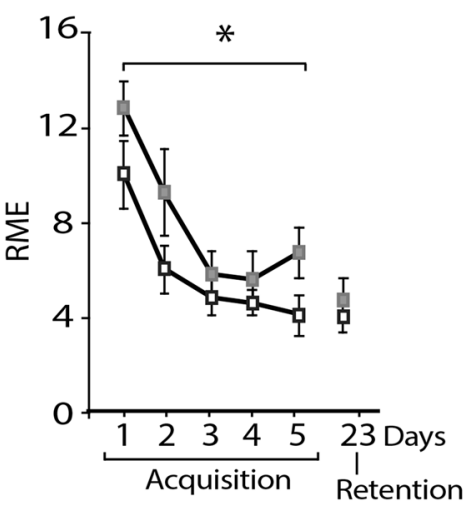

Working Memory Error (WME)

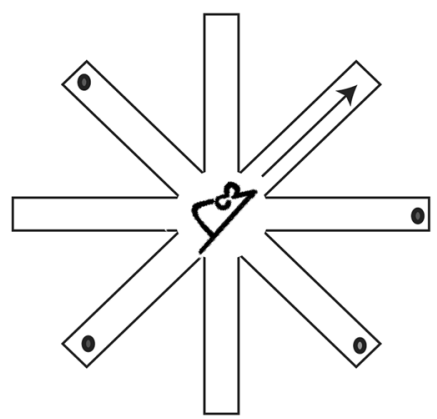

$\mathbf{F}$

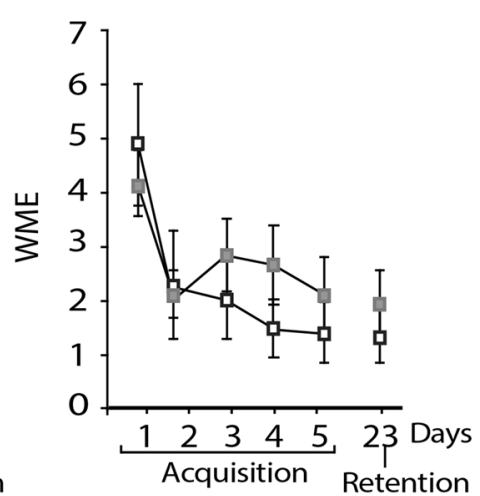

Fig. 5 Analysis of basal and amphetamine-induced locomotion and of spatial memory. Horizontal locomotion (recorded as at least two consecutive photobeam interruptions) before and after saline- (a) and amphetamine- (b) injections; shown 30 minutes prior to injection $(-30$ to -10$)$, injection indicated by time point 0 , and 90 min postinjection (10-90) in $10 \mathrm{~min}$ intervals. Spatial memory testing in the baited radial arm maze. Schematic drawing of the maze depicting a correct choice (left), a reference memory error (RME) (middle) and a working memory error (WME) (right) (see materials and methods for details) (c). Performance of the mice during the acquisition days (1-5) and retention testing (day 23) as indicated by the number of correct choices (left), RMEs (middle) and WMEs (right) (d). Single asterisk $p<0.05$; double asterisk $p<0.001$ (2-way ANOVA) 
Fig. 6 HPLC analysis of DA and its metabolites in dissected brain material. Tissue content of dopamine (DA), 3,4-

Dihydroxyphenyl-acetic acid (DOPAC) and homovanillic acid (HVA) of control (white bars) and cKO (grey bars) mice, all in ng/g wet tissue. Olfactory bulb (a); substantia nigra pars compacta/Ventral tegmental area $(\mathrm{SNc} / \mathrm{VTA})(\mathbf{b})$;

hypothalamus (c); nucleus accumbens (NAcc) $(\mathbf{d})$; caudate putamen $(\mathrm{CAPu})(\mathbf{e})$; prefrontal cortex (f); amygdala (g);

hippocampus (h). Single asterisk $p<0.05$; double asterisk $p<0.001$ (MannWhitney $U$ test)
A
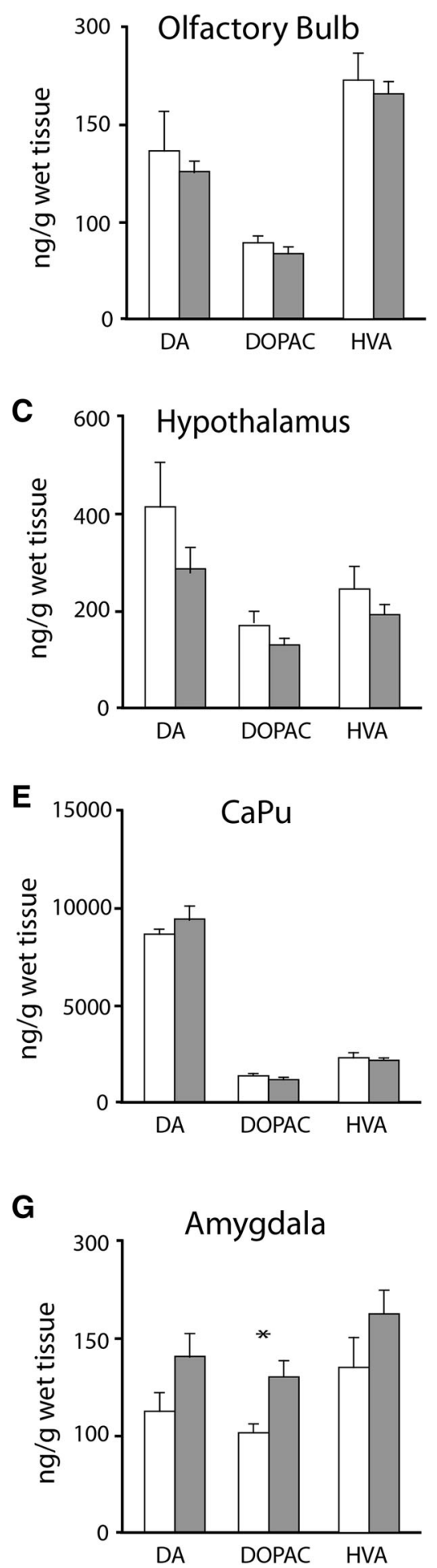

B

Control $\square$ cKO
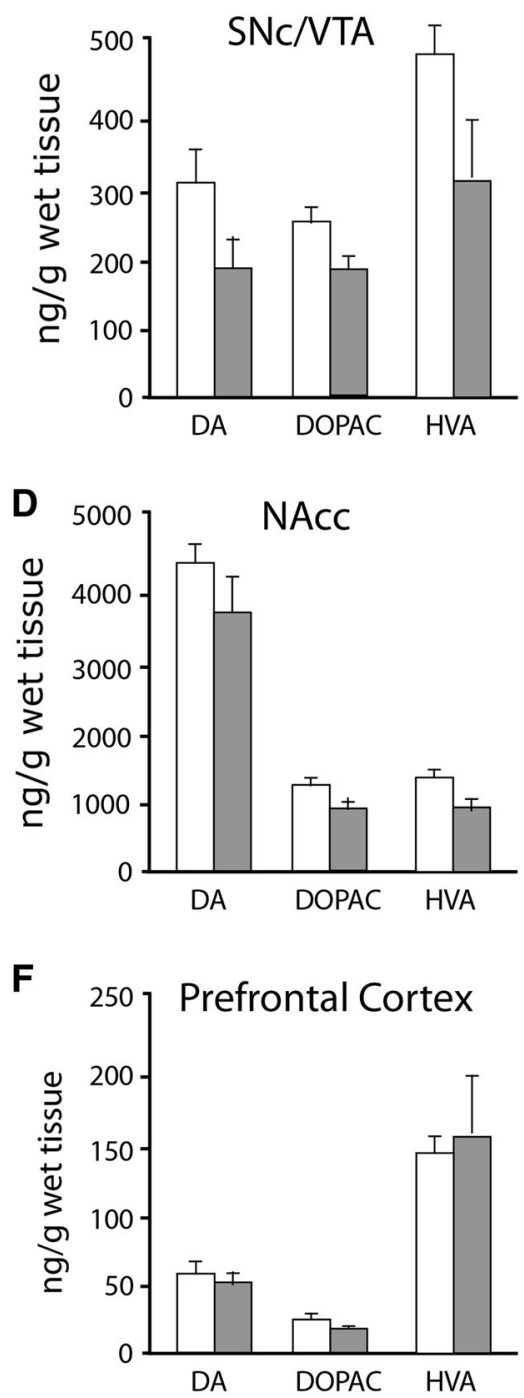

H

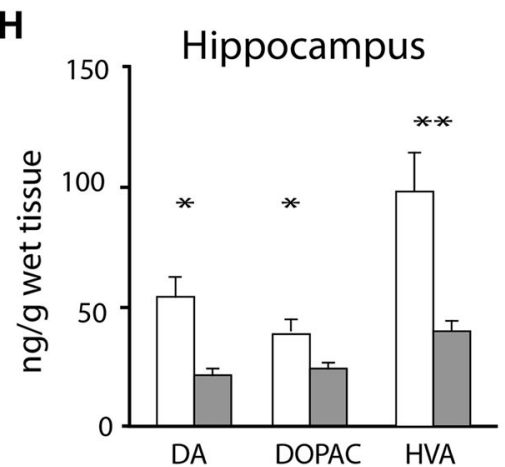

hypothalamus, all of which contain DA neuronal cell bodies, as well as the nucleus accumbens (NAcc), caudate putamen $(\mathrm{CaPu})$, prefrontal cortex (PFC), amygdala and the hippocampus as these regions are known target areas of DA neurons. No difference was observed in DA, DOPAC or HVA concentrations in the olfactory bulb, VTA/SNc, $\mathrm{CaPu}, \mathrm{NAcc}$, hypothalamus or the PFC between $\mathrm{cKO}$ and littermate control mice (Fig. 6a-f). However, a significant increase was observed in DOPAC concentration in the amygdala of cKO mice in comparison to controls 

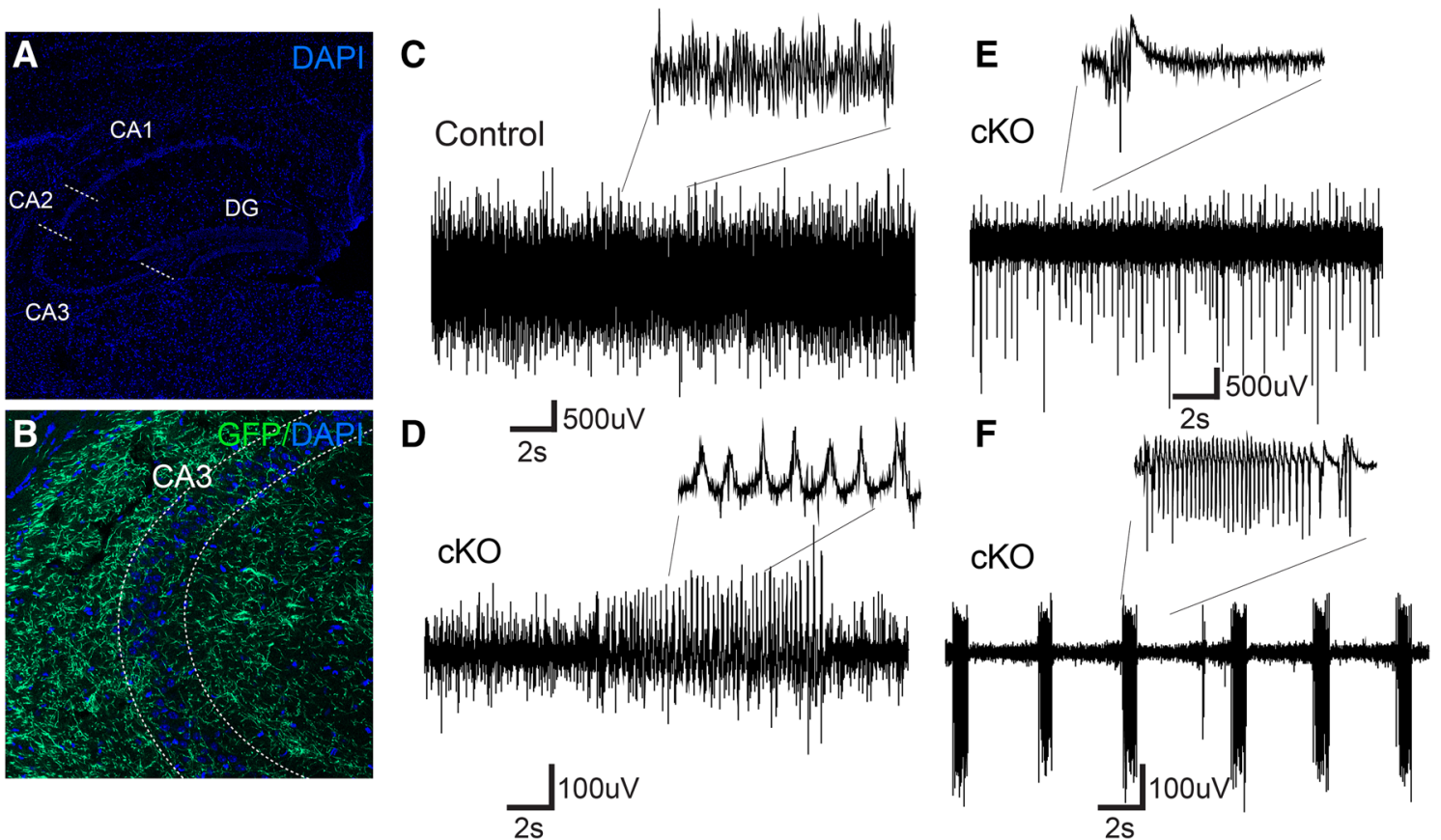

Fig. 7 Local field potential (LFP) recordings in the CA3 of the hippocampal slice preparation. Immunofluorescent analysis of coronal hippocampal sections. Overview of hippocampus regions [CA1, CA2, CA3 and dentate gyrus (DG)] with cell bodies visualized by DAPI (blue) (a); higher magnification close-up image of the CA3 region revealing projections labelled with green fluorescent protein

( $p=0.0426$ ), but not in DA or HVA (Fig. 6g). In contrast, the concentration of DA $(p=0.0311)$, DOPAC $(p=0.0489)$ and HVA $(p=0.0022)$ was all significantly reduced in the hippocampus of $\mathrm{cKO}$ mice in comparison to littermate controls (Fig. 4h).

The observations of reduced DA tissue levels in the hippocampus support our behavioural observation of a possible alteration in the hippocampus due to the lack of Vglut2 expression in TH-Cre active cells.

Hippocampus slices from cKO mice show increased kainate-induced excitability

As mentioned above, Ctrl-Cre-GFP mice show ample THCre-dependent projections throughout the hippocampal formation (Fig. 7a, b), and behavioural phenotyping using the radial maze for assessment of spatial memory function suggests an impairment in the hippocampus. Signalling between the VTA and hippocampus, especially DA release in the hippocampus, has been shown to be important for the formation of long-term memory (Lisman and Grace 2005). The VTA is furthermore involved in the generation of rhythmic activity in the hippocampus (Orzel-Gryglewska et al. 2012). We, therefore, hypothesized that the pattern of network oscillations could be altered in cKO mice. To

(GFP; green) from TH-Cre-reporter activity, cell bodies marked with DAPI (blue) (b). LFP recordings of the CA3 region of hippocampal slices taken from Control and $\mathrm{cKO}$ mice; representative example of a control slice showing stable gamma oscillations (c); three examples of different forms of epileptiform activity observed in CA3 slices of cKO mice $(\mathbf{d}-\mathbf{f})$

investigate this, we recorded local field potential (LFP) in vitro in the CA3 area of the hippocampus by using horizontal slices (Leao et al. 2009). In slices derived from control mice, $100 \mathrm{nM}$ kainate application produced stable gamma oscillations ( 7 in 8 slices from 3 animals, Fig. 7c) and epileptic-like events (Zelano et al. 2013) in one of the slices. In contrast, slices from cKO mice showed profound changes in excitability when perfused with $100 \mathrm{nM}$ kainate (Fig. 7d-f). Kainate application elicited gamma oscillation in only one slice ( $n=8$ slices from 3 animals, $p=0.01$, $Z$ test) while epileptic-like events were recorded in the remaining 7 slices $(n=8$ slices from 3 animals, $p=0.003, Z$ test, Fig. $7 \mathrm{~d}-\mathrm{f}$ ).

These profound differences in CA3 responses to kainate challenge indicate an impairment of cKO mice in the ability to generate stable network oscillations.

\section{Discussion}

The present study focused on investigating the function of Vglut2 expression in neurons that either transiently or stably also express $T H$, the rate-limiting enzyme for catecholamine synthesis. We found that the targeted deletion of Vglut2 in TH-expressing neurons resulted in a memory 
formation-deficit observed as an increased time required to acquire hippocampus-dependent spatial memory and elevated amount of errors produced in the radial arm maze, a finding which could possibly be associated with the observations of decreased DA levels and altered firing pattern in CA3 neurons of the hippocampus.

The role of glutamatergic signalling in cells that express Vglut2 has been investigated using the Cre-LoxP-based conditional knockout technique (Wallén-Mackenzie et al. 2010). A full Vglut2 knockout mouse, driven by the PGKCre transgene, resulted in dysfunctional glutamatergic transmission in the pre-Bötzinger complex causing neonatal lethality due to immediate respiratory failure, thereby demonstrating that Vglut2 expression is necessary for postuterine life (Wallén-Mackenzie et al. 2006). In our extended analysis of VGLUT2 at a midgestational embryonic stage (E12), we now show that this protein is found throughout the brain already at this early developmental stage, putatively supporting a broader role in establishment of the nervous system than previously recognized, but which could gain from further exploration. For gene targeting of Vglut2 expression within DA neurons specifically, DAT-Cre transgenic mice, of which there exists a couple of variants, have been used by breeding to floxed Vglut $2^{f / f}$ mice, of which there also exist a few variants (Birgner et al. 2010; Fortin et al. 2012; Hnasko et al. 2010). Data have generally been interpreted based on the assumption that DAT-Cre will be active in all DA neurons and similar assumptions are common in neighbouring research fields where DAT-Cre mice are used to target other gene expression in DA neurons [e.g. the selective targeting of components of the glutamatergic machinery; reviewed in Rodriguez Parkitna and Engblom (2012)]. However, it is well known that not all $T H$-expressing neurons of the VTA area express DAT (Lammel et al. 2008; Sesack et al. 1998). Thus, via DAT-Cre-mediated deletion of Vglut2 in DA neurons, which gives rise to altered responses to both sugar-rich food and psychostimulants, the so-called "TH-Vglut2 Class 2" population, which lacks $D A T$ expression, has probably remained undisturbed, and the observed reward-related phenotype has been due to targeted deletion of Vglut2 in the "TH-Vglut2 Class 1" population only. As curious as this is, the situation becomes slightly more complex when using a TH-Cre transgene, as we did here, to target Vglut2 expression. This is brought about not only because $T H$ is endogenously expressed in all catecholaminergic neurons thereby targeting also the $\mathrm{C} 1, \mathrm{C} 2$ and $\mathrm{C} 3$ groups that have been reported to also contain some Vglut2-expressing cells (Stornetta et al. 2002a, b), and which therefore may contribute to the behavioural phenotype, but because the $\mathrm{TH}$ promoter shows a complex temporal pattern of activity that gives rise to "promiscuous", but transient, activation of the
Cre recombinase also in non-catecholaminergic cells during early development (see Illustration Fig. 8). Such populations include both non-neuronal (e.g. germ cells and heart cells) and neuronal cells (e.g. the dorsal and inferior colliculus, the pontine reticulotegmental nuclei, tegmental and parabrachial nuclei, cerebellar Purkinje cells, mammillary nucleus, and also scattered cells throughout the cortex, the lateral and medial thalamus, and the striatum), i.e. both inhibitory and excitatory populations; some of which may coexpress Vglut2. While the normal life span of the cKO mice, as well as the normal activational level of the mice in the both the EPM and FST tests and when the mice are monitored in automated locomotor chambers, are findings suggestive of an absence of a critical role for Vglut2 in the cardiorespiratory C1-3 neurons, the promiscuity of the TH promoter may present to be a greater challenge. Indeed, we have previously shown that activation of Cre in the DRG due to transient activation of the TH-promoter caused an itch phenotype in a subset of the cKO mice (Lagerström et al. 2010). By selecting non-itchstruck mice in the current study, we instead found a rather unexpected way to take advantage of the promiscuous $\mathrm{TH}$ promoter. This approach enabled, for the first time, the targeting within all three VTA-VGLUT2 populations, i.e. both populations ("TH-Vglut2 Class 1" and "TH-Vglut2 Class 2") that express stable $T H$ which can be detected as protein by IHC at any stage of life as well as the population that is characterized by absence of stable $T H$ expression ("Vglut2-only"), but which, as it now turned out by the identification of the $\mathrm{KO}$ allele also in these cells, had experienced TH-Cre activity during early embryo stages (see Illustration in Fig. 8 for a summary of the Vglut2expressing cell groups found in the ventral midbrain at E12 and $\mathrm{P} 1$, respectively). In situ hybridization failed to detect a significant difference between adult $\mathrm{cKO}$ and control mice, likely due to the low number of animals used and/or the fact that the in situ probe bound to the untargeted exons 1-3 as well as downstream targeted exons 4-6, possibly resulting in similar binding efficiency between genotypes. However, using semi-quantitative RT-PCR on single cell material, as we have also done before to verify targeting of the Vglut2 gene (Birgner et al. 2010), the KO allele was readily detected. This $\mathrm{TH}-\mathrm{Cre}$-mediated targeting of Vglut2 gave rise to a $97 \%$ recombination efficiency in the VTA/SNc area and included all three categories of populations expressing the TH-Cre-transgene, while DAT-Cremediated targeting did not include the "Vglut2-only" population but efficiently targeted Vglut2 in DAT-Creexpressing cells (82\% efficiency) in the VTA/SNc area (Birgner et al. 2010). One important caveat of the current study concerns the extent of TH-Cre activity in the three VTA subpopulations. Thus, while the TH-Cre-mediated targeting was highly efficient within cells expressing the 
A

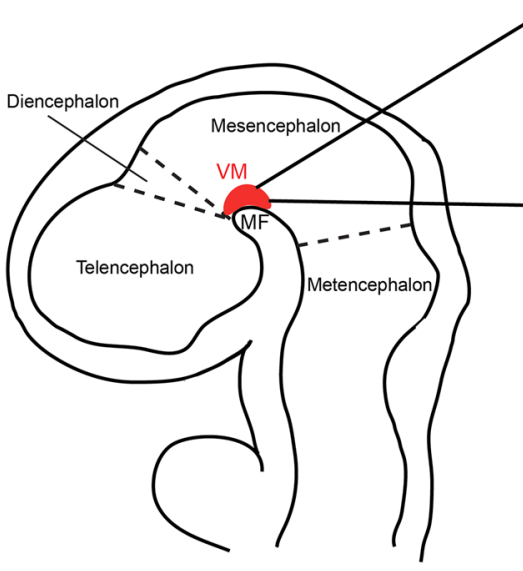

B

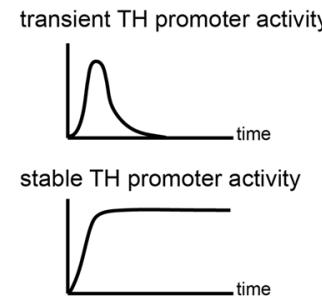

$\mathrm{E} 12$

$\mathrm{TH}$ $\mathrm{TH}+$ Vglut2 vglut2

P1<smiles>[OH+]</smiles>
$\mathrm{TH}+\mathrm{DAT}$ TH + DAT + Vglut2 ("TH-Vglut2 Class 1") TH + Vglut2 ("TH-Vglut2 Class 2") Vglut2 ("Vglut2-only")
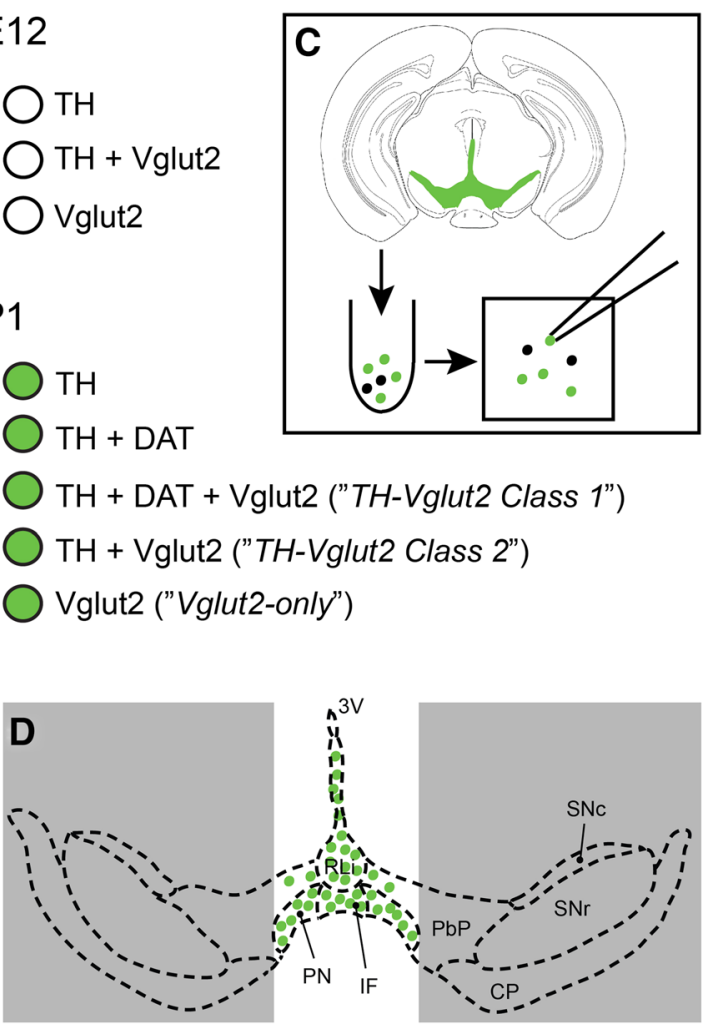

Fig. 8 Illustration of the analysis of subpopulations in the ventral midbrain. a Schematic drawing of an E12 mouse embryo (seen in sagittal view) in which the ventral midbrain (VM) area, where the dopamine (DA) neurons develop, is highlighted in red. In our analysis (Fig. 1), we looked at the colocalization of Vglut2 mRNA with TH immunoreactivity and found cells expressing both and either of these genes, i.e. TH only, Vglut 2 only and TH-Vglut 2 together. At this stage, DAT is not expressed, and was therefore not analysed. b Representation of the two known phases of TH promoter activity, a transient phase which is not specific to cells that will develop into catecholaminergic neurons, and a stable phase which gives rise to the stable $\mathrm{TH}$ expression in catecholaminergic neurons. c Schematic drawing of the single cell selection we performed at P1 (Fig. 3) to analyse gene expression in TH-Cre cells by RT-PCR. Coronal midbrain slices of Ctrl-Cre-GFP and cKO-Cre-GFP mice, in which TH-Cre activity has led to expression of the Cre-double reporter $\mathrm{Tau}^{\mathrm{mGFP}}$ thus enabling localization of these cells by GFP in fluorescent microscope, were prepared on vibratome and the entire GFP-positive ventral area [encompassing the A10 area (the rostral linear nucleus of the raphé nuclei (RLi); paranigral nucleus $(\mathrm{PN})$; interfascicular nucleus (IF); medial parabrachial pigmented nucleus $(\mathrm{PbP})]$ together with the lateral VTA and substantia nigra pars compacta $(\mathrm{SNc})$, but not substantia nigra pars compacta $(\mathrm{SNr})$ was dissected and triturated into single cell solution from which single GFP-positive cells were picked. d The subsequent RT-PCR analysis using Vglut2 primers (designed to recognize mRNA both from the wildtype and knockout in the same reaction), DAT primers and $\mathrm{TH}$ primers led us to conclude that TH-Cre is active in several populations of cells in the GFP-positive dissected area of the ventral midbrain. Based on ours (Fig. 2) and previous studies that have shown that, in the adult, Vglut 2 is most highly expressed in the A10 nuclei and not in the lateral VTA and SNc, and our observation of TH-Cre activity (detected as $\beta$-galacosidase in Fig. 3) suggest that the Vglut2 mRNA we detect is derived from the A10 nuclei. We cannot rule out that the Vglut2 we observe is derived from the lateral structures (shadowed in grey) that were also dissected, although this seems less likely. In summary, we found single GFP-positive cells expressing the combination of TH, Vglut 2 and DAT as illustrated by the green dots in the figure: TH only; TH and DAT; TH and DAT and Vglut2; TH and Vglut2 but no DAT; Vglut2 only. Cells showing TH and DAT and Vglut2 have previously been termed " $T H-V g l u t 2$ Class 1 " and cells showing TH and Vglut2 but no DAT have been termed "TH-Vglut2 Class 2", a terminology we adapted and refer to in the current study. All literature referred to is listed in text
TH-Cre transgene of each subpopulation, we cannot rule the existence of Vglut2-expressing cells within any of the VTA subpopulations not expressing the TH-Cre transgene; such cells would remain untargeted in this approach. Behavioural phenotyping of the new TH-Cre-mediated Vglut2 cKO mice showed the same absence of anxiety- and depression-related phenotypes as the mice carrying a DATCre-mediated gene targeting of Vglut2, but the behavioural profile was the "opposite" when it came to amphetamine- induced psychomotor response versus hippocampusdependent spatial memory. The lack of alteration in amphetamine-response was unexpected, given the strong phenotype of the Vglut $2^{f f f ; D A T-C r e}$ cKO mice. This finding might be explained by the temporal (TH-Cre activity precedes that of DAT-Cre) or the spatial (selectivity) difference between the two Cre mouse lines (or both). For example, by carrying the potential of deleting Vglut 2 expression already from midgestation, temporally defined 
developmental compensations may take place in the Vglut $2^{f f f}$ TH-Cre mice that will no longer be possible upon targeting in the Vglut $2^{f f f ; D A T-C r e}$ mice, which occurs several days later. The spatially broader targeting of the TH-Cre over the DAT-Cre, the latter of which occurs only in subsets of DA cells and not at all in Vglut2-only cells, may also contribute to the difference in reward-related responses, although mechanisms remain to be established. Another important factor that has to be taken into account is the difference in genetic backgrounds of the TH-Cre (pure C57/B16 J background) and DAT-Cre [mixed C57BL/6 J-SV129 background (Birgner et al. 2010)] mice which, when bred to the Vglut $2^{f / f}$ mice (mixed C57BL/6 JSV129 background), give rise to offspring of which the Vglut $2^{f f f ; T H-C r e}$ mice will contain a higher level of C57/ B16 J than the Vglut fff;DAT-Cre mice. Thus, both selectivity and genetic background might contribute to the observed differences in reward-related response between the Vglut $2^{f f ;} ;$ TH-Cre mice and Vglut $2^{f f f ; D A T-C r e}$ mice.

A deeper understanding of the observed complex hippocampal phenotype will require additional approaches, but will be discussed briefly here. Taken together, three independent results point towards a hippocampus-related phenotype in the TH-Cre-mediated cKO mice; the slower acquisition and the accentuated error rate in the radial arm maze, a spatial memory test designed to assay hippocampus function (Meck et al. 1984); the significantly lower DA tissue levels observed by electrochemical detection in homogenates prepared from the hippocampus (while no other region containing either DA cell bodies or projection terminals showed similar alterations); and the increased sensitivity to the ionotropic glutamate receptor agonist kainate, leading to seizure-like activity in slice preparations obtained from cKO brains. In recent studies, it was shown in rats that severing of the signalling from the VTA to the hippocampus via the local administration of lidocaine (Mahmoodi et al. 2011) or baclofen (Martig and Mizumori 2011), resulted in a decreased performance in memory tests. Neither study showed motivational or movement disruptions, but an increase in errors and an elevated number of trials required to reach the acquisition criterion in memory tasks (Mahmoodi et al. 2011; Martig and Mizumori 2011). It could therefore be proposed that the memory deficits seen in our cKO mice may be caused by the disruption of the DA signalling between the VTA and hippocampus. Further, in a previous study, 6-hydroxydopamine lesioning of the VTA in rats resulted in the loss of approximately $50 \%$ of DA neurons leading to a $74 \%$ reduction in DA levels in the hippocampus as well as an $83 \%$ loss in the frontal cortex (Wisman et al. 2008). The loss of DA was associated with a poorer reference memory performance, with repeated trials required for the rats to acquire the task (Wisman et al. 2008). These findings highlight the important role of the VTA DA system in learning and consolidation of memory. Importantly, our observation of a decreased capability of the cKO mice during the acquisition phase in the radial arm maze, and the observations we make in the seizure-prone slice preparation could also be due to a loss of glutamatergic signalling, by the targeting of "Vglut2-only" cells and the glutamatergic, instead of the dopaminergic, component of the glutamate/DA cophenotypic cells. Electrical stimulation of the VTA has previously been shown to elicit theta oscillations, important for long-range synchronization of neuronal activity, in the hippocampus (Orzeł-Gryglewska et al. 2012). Therefore, disruption of glutamatergic signalling originating from the VTA can lead to reduced activity in the hippocampal area. Known effects of activity deprivation in the hippocampus are downregulation of $\mathrm{GABA}_{\mathrm{A}}$ receptors (Kilman et al. 2002) and reduction of GABA immunoreactivity, as shown in neocortical and hippocampal culture neurons (Marty et al. 1997). Maintenance of homeostasis is likely driven by a similar mechanism in the hippocampus of cKO mice. This would, as a consequence, lead to less activation of the hippocampal circuits through the VTA and an adaption of the circuitry that might already start during embryonal development. Since projections from the VTA are severed in hippocampal slice preparations, the remaining circuit is solely dependent on inhibitory and excitatory connections within the hippocampus. As a putative result of a compensatory downregulation of inhibitory components in the cKO mice upon the deprivation of VTA-derived activity, isolated hippocampal could exhibit a general overexcitation. In the presence of $100 \mathrm{nM}$ kainate, a possible imbalance in the excitation/ inhibition ratio could therefore lead to the generation of epileptiform discharges observed in the $\mathrm{cKO}$ mice, while control mice show normal gamma oscillations. Notably, given the promiscuous nature of the $\mathrm{TH}$ promoter as discussed above, it is conceivable that the hippocampusrelated effects are independent of any alterations occurring in Vglut2 expression in the VTA area, but are derived from alterations in Vglut2 expression elsewhere. A broader range of genetic tools for ascertaining more selective gene targeting events, both spatially and temporally, should prove helpful in resolving the functional correlation between glutamate/dopamine transmission from the VTA and the herein described hippocampus-related phenotypes.

In summary, using a TH-Cre knock-in strategy which gives rise to Cre activity both in stable $T H$-expressing neurons and in cells that only transiently express $T H$ during early development, we found a way to target Vglut2 gene expression within all three VTA-VGLUT2 populations identified in the medial aspects of the A10 area. Both the unexpected absence of altered psychostimulant-induced behavioural activation and the identification of the strong 
deficiency in hippocampus function require further investigation, not least due to the promiscuity of the TH-Cre transgene which is expressed in several non-neuronal and neuronal populations in addition to the VTA. Today, most studies, even those using optogenetics to control neural activity, rely on DAT-Cre or TH-Cre for targeting of DA cells. With the accelerating gain of knowledge of various subpopulations within the A10 area, it is becoming increasingly evident that the field would benefit from a broader selection of genetic tools to enable further characterization of the physiological roles of these different neuronal groups.

Acknowledgments We thank Prof. Ted Ebendal (Univ. of Uppsala, Sweden) and Prof. Sylvia Arber (Univ. of Basel, Switzerland) for generously sharing the TH-ires-Cre and tau-mGFP mouse lines, respectively; Prof. Bruno Gasnier for the kind gift of VIAAT antibody; Dr. Madeleine le Grevés for experimental advice; and Li Li and Emily Sällström for technical assistance. This work was supported by grants from the Swedish Medical Research Council (2007-5742, 2011-4747), Uppsala University, the Swedish Brain Foundation, Parkinsonfonden, and the foundations of Major Gösta Lind, Ảke Wiberg, Åhlén, and Bertil Hållsten. MM and JMT were supported by the Intramural Research Program of the National Institute on Drug Abuse.

Conflict of interest The authors declare no conflict of interest.

Open Access This article is distributed under the terms of the Creative Commons Attribution License which permits any use, distribution, and reproduction in any medium, provided the original author(s) and the source are credited.

\section{References}

Alsiö J, Nordenankar K, Arvidsson E, Birgner C, Mahmoudi S, Halbout B, Smith C, Fortin GM, Olson L, Descarries L, Trudeau LE, Kullander K, Levesque D, Wallén-Mackenzie Å (2011) Enhanced sucrose and cocaine self-administration and cueinduced drug seeking after loss of VGLUT2 in midbrain dopamine neurons in mice. J Neurosci 31(35):12593-12603. doi:10.1523/JNEUROSCI.2397-11.2011

Birgner C, Nordenankar K, Lundblad M, Mendez JA, Smith C, le Greves M, Galter D, Olson L, Fredriksson A, Trudeau LE, Kullander K, Wallén-Mackenzie Å (2010) VGLUT2 in dopamine neurons is required for psychostimulant-induced behavioral activation. Proc Natl Acad Sci U S A 107(1):389-394. doi:10. 1073/pnas.0910986107

Crusio WE (2004) Flanking gene and genetic background problems in genetically manipulated mice. Biol Psychiatry 56(6):381-385. doi:10.1016/j.biopsych.2003.12.026

El Mestikawy S, Wallén-Mackenzie A, Fortin GM, Descarries L, Trudeau LE (2011) From glutamate co-release to vesicular synergy: vesicular glutamate transporters. Nat Rev Neurosci 12(4):204-216. doi:10.1038/nrn2969

Fauchey V, Jaber M, Caron MG, Bloch B, Le Moine C (2000) Differential regulation of the dopamine D1, D2 and D3 receptor gene expression and changes in the phenotype of the striatal neurons in mice lacking the dopamine transporter. Eur $\mathrm{J}$ Neurosci 12(1):19-26
Fields HL, Hjelmstad GO, Margolis EB, Nicola SM (2007) Ventral tegmental area neurons in learned appetitive behavior and positive reinforcement. Annu Rev Neurosci 30:289-316. doi:10. 1146/annurev.neuro.30.051606.094341

Fortin GM, Bourque MJ, Mendez JA, Leo D, Nordenankar K, Birgner C, Arvidsson E, Rymar VV, Berube-Carriere N, Claveau AM, Descarries L, Sadikot AF, Wallén-Mackenzie A, Trudeau LE (2012) Glutamate corelease promotes growth and survival of midbrain dopamine neurons. J Neurosci 32(48):17477-17491. doi:10.1523/JNEUROSCI.1939-12.2012

Fremeau RT Jr, Voglmaier S, Seal RP, Edwards RH (2004) VGLUTs define subsets of excitatory neurons and suggest novel roles for glutamate. Trends Neurosci 27(2):98-103. doi:10.1016/j.tins. 2003.11.005

Gras C, Amilhon B, Lepicard ÈM, Poirel O, Vinatier J, Herbin M, Dumas S, Tzavara ET, Wade MR, Nomikos GG, Hanoun N, Saurini F, Kemel M-L, Gasnier B, Giros B, Mestikawy SE (2008) The vesicular glutamate transporter VGLUT3 synergizes striatal acetylcholine tone. Nat Neurosci 11(3):292-300. doi:10. 1038/nn2052

Hioki H, Fujiyama F, Taki K, Tomioka R, Furuta T, Tamamaki N, Kaneko T (2003) Differential distribution of vesicular glutamate transporters in the rat cerebellar cortex. Neuroscience 117(1):1-6

Hippenmeyer S, Vrieseling E, Sigrist M, Portmann T, Laengle C, Ladle DR, Arber S (2005) A developmental switch in the response of DRG neurons to ETS transcription factor signaling. PLoS Biol 3(5):e159. doi:10.1371/journal.pbio.0030159

Hnasko TS, Edwards RH (2012) Neurotransmitter corelease: mechanism and physiological role. Annu Rev Physiol 74:225-243. doi:10.1146/annurev-physiol-020911-153315

Hnasko TS, Chuhma N, Zhang H, Goh GY, Sulzer D, Palmiter RD, Rayport S, Edwards RH (2010) Vesicular glutamate transport promotes dopamine storage and glutamate corelease in vivo. Neuron 65(5):643-656. doi:10.1016/j.neuron.2010.02.012

Hnasko TS, Hjelmstad GO, Fields HL, Edwards RH (2012) Ventral tegmental area glutamate neurons: electrophysiological properties and projections. J Neurosci 32(43):15076-15085. doi:10. 1523/JNEUROSCI.3128-12.2012

Ikemoto S (2007) Dopamine reward circuitry: two projection systems from the ventral midbrain to the nucleus accumbens-olfactory tubercle complex. Brain Res Rev 56(1):27-78. doi:10.1016/j. brainresrev.2007.05.004

Kawano M, Kawasaki A, Sakata-Haga H, Fukui Y, Kawano H, Nogami H, Hisano S (2006) Particular subpopulations of midbrain and hypothalamic dopamine neurons express vesicular glutamate transporter 2 in the rat brain. J Comp Neurol 498(5):581-592. doi:10.1002/cne.21054

Kilman V, Rossum MCWv, Turrigiano GG (2002) Activity deprivation reduces miniature IPSC amplitude by decreasing the number of postsynaptic GABAA receptors clustered at neocortical synapses. J Neurosci 22(4):1328-1337

Lagerström MC, Rogoz K, Abrahamsen B, Persson E, Reinius B, Nordenankar K, Olund C, Smith C, Mendez JA, Chen ZF, Wood JN, Wallén-Mackenzie $\AA$, Kullander K (2010) VGLUT2dependent sensory neurons in the TRPV1 population regulate pain and itch. Neuron 68(3):529-542. doi:10.1016/j.neuron. 2010.09.016

Lammel S, Hetzel A, Häckel O, Jones I, Liss B, Roeper J (2008) Unique properties of mesoprefrontal neurons within a dual mesocorticolimbic dopamine system. Neuron 57(5):760-773. doi:10.1016/j.neuron.2008.01.022

Leao RN, Tan HM, Fisahn A (2009) Kv7/KCNQ channels control action potential phasing of pyramidal neurons during hippocampal gamma oscillations in vitro. J Neurosci 29(42):13353-13364. doi:10.1523/JNEUROSCI.1463-09.2009 
Lendahl U, Zimmerman LB, McKay RD (1990) CNS stem cells express a new class of intermediate filament protein. Cell 60(4):585-595

Li X, Qi J, Yamaguchi T, Wang HL, Morales M (2013) Heterogeneous composition of dopamine neurons of the rat A10 region: molecular evidence for diverse signaling properties. Brain Struct Funct 218(5):1159-1176. doi:10.1007/s00429-012-0452-z

Lindeberg J, Usoskin D, Bengtsson H, Gustafsson A, Kylberg A, Soderstrom S, Ebendal T (2004) Transgenic expression of Cre recombinase from the tyrosine hydroxylase locus. Genesis 40(2):67-73. doi:10.1002/gene.20065

Lisman JE, Grace AA (2005) The hippocampal-VTA loop: controlling the entry of information into long-term memory. Neuron 46(5):703-713. doi:10.1016/j.neuron.2005.05.002

Mahmoodi M, Shahidi S, Hasanein P (2011) Involvement of the ventral tegmental area in the inhibitory avoidance memory in rats. Physiol Behav 102(5):542-547. doi:10.1016/j.physbeh. 2011.01.011

Martig AK, Mizumori SJY (2011) Ventral tegmental area disruption selectively affects CA1/CA2 but not CA3 place fields during a differential reward working memory task. Hippocampus 21(2):172-184. doi:10.1002/hipo.20734

Marty S, Da Penha Berzaghi M, Berninger B (1997) Neurotrophins and activity-dependent plasticity of cortical interneurons. Trends Neurosci 20(5):198-202. doi:10.1016/s0166-2236(96)01026-0

McIntire SL, Reimer RJ, Schuske K, Edwards RH, Jorgensen EM (1997) Identification and characterization of the vesicular GABA transporter. Nature 389(6653):870-876. doi:10.1038/39908

Meck WH, Church RM, Olton DS (1984) Hippocampus, time, and memory. Behav Neurosci 98(1):3-22

Orzeł-Gryglewska J, Kuśmierczak M, Majkutewicz I, Jurkowlaniec E (2012) Induction of hippocampal theta rhythm by electrical stimulation of the ventral tegmental area and its loss after septum inactivation. Brain Res 1436:51-67. doi:10.1016/j.brainres.2011. 12.003

Rodriguez Parkitna J, Engblom D (2012) Addictive drugs and plasticity of glutamatergic synapses on dopaminergic neurons: what have we learned from genetic mouse models? Front Mol Neurosci 5:89. doi:10.3389/fnmol.2012.00089

Sagne C, El Mestikawy S, Isambert MF, Hamon M, Henry JP, Giros B, Gasnier B (1997) Cloning of a functional vesicular GABA and glycine transporter by screening of genome databases. FEBS Lett 417(2):177-183

Sesack SR, Hawrylak VA, Matus C, Guido MA, Levey AI (1998) Dopamine axon varicosities in the prelimbic division of the rat prefrontal cortex exhibit sparse immunoreactivity for the dopamine transporter. J Neurosci 18(7):2697-2708

Stornetta RL, Sevigny CP, Guyenet PG (2002a) Vesicular glutamate transporter DNPI/VGLUT2 mRNA is present in C1 and several other groups of brainstem catecholaminergic neurons. J Comp Neurol 444(3):191-206. doi:10.1002/cne.10141

Stornetta RL, Sevigny CP, Schreihofer AM, Rosin DL, Guyenet PG (2002b) Vesicular glutamate transporter DNPI/VGLUT2 is expressed by both $\mathrm{C} 1$ adrenergic and nonaminergic presympathetic vasomotor neurons of the rat medulla. J Comp Neurol 444(3):207-220. doi:10.1002/cne.10142

Tagliaferro P, Morales M (2008) Synapses between corticotropinreleasing factor-containing axon terminals and dopaminergic neurons in the ventral tegmental area are predominantly glutamatergic. J Comp Neurol 506(4):616-626. doi:10.1002/ cne. 21576

Tsien JZ, Chen DF, Gerber D, Tom C, Mercer EH, Anderson DJ, Mayford M, Kandel ER, Tonegawa S (1996) Subregion- and cell type-restricted gene knockout in mouse brain. Cell 87(7):1317-1326

Wallén-Mackenzie A, Gezelius H, Thoby-Brisson M, Nygard A, Enjin A, Fujiyama F, Fortin G, Kullander K (2006) Vesicular glutamate transporter 2 is required for central respiratory rhythm generation but not for locomotor central pattern generation. J Neurosci 26(47):12294-12307. doi:10.1523/JNEUROSCI. 3855-06.2006

Wallén-Mackenzie Å, Nordenankar K, Fejgin K, Lagerstrom MC, Emilsson L, Fredriksson R, Wass C, Andersson D, Egecioglu E, Andersson M, Strandberg J, Lindhe O, Schioth HB, Chergui K, Hanse E, Langstrom B, Fredriksson A, Svensson L, Roman E, Kullander K (2009) Restricted cortical and amygdaloid removal of vesicular glutamate transporter 2 in preadolescent mice impacts dopaminergic activity and neuronal circuitry of higher brain function. J Neurosci 29(7):2238-2251. doi:10.1523/ JNEUROSCI.5851-08.2009

Wallén-Mackenzie ̊, Wootz H, Englund H (2010) Genetic inactivation of the vesicular glutamate transporter 2 (VGLUT2) in the mouse: what have we learnt about functional glutamatergic neurotransmission? Ups J Med Sci 115(1):11-20. doi:10.3109/ 03009730903572073

Wang HL, Morales M (2008) Corticotropin-releasing factor binding protein within the ventral tegmental area is expressed in a subset of dopaminergic neurons. J Comp Neurol 509(3):302-318. doi:10.1002/cne.21751

Wang MZ, Jin P, Bumcrot DA, Marigo V, McMahon AP, Wang EA, Woolf T, Pang K (1995) Induction of dopaminergic neuron phenotype in the midbrain by Sonic hedgehog protein. Nat Med 1(11):1184-1188

Wisman LA, Sahin G, Maingay M, Leanza G, Kirik D (2008) Functional convergence of dopaminergic and cholinergic input is critical for hippocampus-dependent working memory. J Neurosci 28(31):7797-7807. doi:10.1523/JNEUROSCI.1885-08.2008

Wolfer DP, Crusio WE, Lipp HP (2002) Knockout mice: simple solutions to the problems of genetic background and flanking genes. Trends Neurosci 25(7):336-340

Yamaguchi T, Sheen W, Morales M (2007) Glutamatergic neurons are present in the rat ventral tegmental area. Eur $\mathrm{J}$ Neurosci 25(1):106-118. doi:10.1111/j.1460-9568.2006.05263.x

Ye W, Shimamura K, Rubenstein JL, Hynes MA, Rosenthal A (1998) FGF and Shh signals control dopaminergic and serotonergic cell fate in the anterior neural plate. Cell 93(5):755-766

Zelano J, Mikulovic S, Patra K, Kuhnemund M, Larhammar M, Emilsson L, Leao R, Kullander K (2013) The synaptic protein encoded by the gene Slc10A4 suppresses epileptiform activity and regulates sensitivity to cholinergic chemoconvulsants. Exp Neurol 239:73-81. doi:10.1016/j.expneurol.2012.09.006

Zetterström RH, Solomin L, Jansson L, Hoffer BJ, Olson L, Perlmann $\mathrm{T}$ (1997) Dopamine neuron agenesis in Nurr1-deficient mice. Science 276(5310):248-250 